This document was prepared in conjunction with work accomplished under Contract No. DE-AC09-96SR18500 with the U. S. Department of Energy.

\title{
DISCLAIMER
}

This report was prepared as an account of work sponsored by an agency of the United States Government. Neither the United States Government nor any agency thereof, nor any of their employees, nor any of their contractors, subcontractors or their employees, makes any warranty, express or implied, or assumes any legal liability or responsibility for the accuracy, completeness, or any third party's use or the results of such use of any information, apparatus, product, or process disclosed, or represents that its use would not infringe privately owned rights. Reference herein to any specific commercial product, process, or service by trade name, trademark, manufacturer, or otherwise, does not necessarily constitute or imply its endorsement, recommendation, or favoring by the United States Government or any agency thereof or its contractors or subcontractors. The views and opinions of authors expressed herein do not necessarily state or reflect those of the United States Government or any agency thereof. 
WSRC-TR-2005-00182, Rev. 0

Keywords: Salt processing, solvent extraction, SWPF, DWPF, MCU

Retention: Permanent

\section{Examination of Organic Carryover from 2-cm Contactors to Support the Modular CSSX Unit}

Charles A. Nash

Michael A. Norato

D. Douglas Walker

Robert A. Pierce

Ronnye A. Eubanks

James D. Clark

Wilson M. Smith, Jr.

Stephen L. Crump

D. Zane Nelson

Samuel D. Fink

Thomas B. Peters

Cecil G. May

David T. Herman

Henry L. Bolton

April 29, 2005

Westinghouse Savannah River Company

Savannah River Site

Aiken, SC 29808

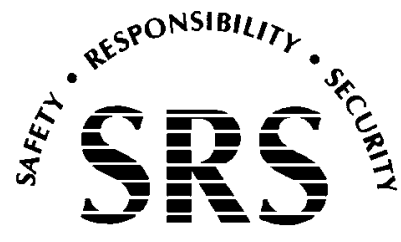

SAVANNAH RIVER SITE

Prepared for the U.S. Department of Energy Under

Contract Number DE-AC09-96SR18500 


\section{EXECUTIVE SUMMARY}

A bank of four 2-cm centrifugal contactors was operated in countercurrent fashion to help address questions about organic carryover for the Modular Caustic Side Solvent Extraction (CSSX) Unit (MCU). The contactors, having weirs sized for strip operation, were used to examine carryover for both strip effluent (SE) and decontaminated salt solution (DSS). Since only one bank of contactors was available in the short time frame of this work, the organic phase and only one aqueous phase were present in the flow loops at a time. Personnel maintained flowsheet-typical organic phase to aqueous phase (O:A) flow ratios when varying flow rates. Solvent from two different batches were tested with strip solution. In addition, potential mitigations of $\mathrm{pH}$ adjustment and coalescing media were examined.

The experiment found that organic carryover after decanting averaged $220 \mathrm{ppm}$ by mass with a range of 74 to $417 \mathrm{ppm}$ of Isopar ${ }^{\circledR} \mathrm{L}$ for strip effluent (SE)/organic solvent contacts. These values are based on measured modifier. Values were bounded by a value of $95 \mathrm{ppm}$ based upon Isopar ${ }^{\circledR} \mathrm{L}$ values as reported. The higher modifier-based numbers are considered more reliable at this time. Carryover of Isopar ${ }^{\circledR}$ L in DSS simulant averaged 77 ppm by mass with a range of 70 to $88 \mathrm{ppm}$ of Isopar ${ }^{\circledR} \mathrm{L}$ based on modifier content. The carryover was bounded by a value of $19 \mathrm{ppm}$ based upon Isopar ${ }^{\circledR} \mathrm{L}$ values as reported. More work is needed to resolve the discrepancy between modifier and Isopar ${ }^{\circledR}$ L values.

The work did not detect organic droplets greater than 18 microns in SE. Strip output contained droplets down to 0.5 micron in size. Droplets in DSS were almost monodisperse by comparison, having a size range $4.7+/-1.6$ micron in one test and $5.2+/-0.8$ micron in the second demonstration. Optical microscopy provided qualitative results confirming the integrity of droplet size measurements in this work.

Acidic or basic adjustments of aqueous strip solution from $\mathrm{pH} 3$ to 1 and from $\mathrm{pH} 3$ to 11 were not effective in clarifying the aqueous dispersions of organic droplets. Use of a 0.7micron rated glass fiber filter of $3 / 4 \mathrm{~mm}$ thickness under gravity flow provided significant reduction in organic content and increased clarity. A 2 inch element stack of "Teflon ${ }^{\circledR}$ Fiber Interceptor-Pak ${ }^{\mathrm{TM}}$ " media from ACS Separations, Inc. was not effective in clarifying DSS simulant. 
WSRC-TR-2005-00182, rev. 0

Page 4 of 37

Examination of Organic Carryover from 2-cm Contactors to Support the Modular CSSX Unit

\section{Contents}

EXECUTIVE SUMMARY

INTRODUCTION

Sub-team A Membership $\quad 7$

EXPERIMENTAL APPROACH

Work Specification, Safety, and Quality Level 7

Analytical Services $\quad 7$

Particle Size Distribution (PSD) for Droplet Size $\quad 7$

Optical Microscopy $\quad 8$

Organic content $\quad 9$

$\begin{array}{lr}\text { Turbidity } & 10\end{array}$

$\begin{array}{ll}\text { Experimental Equipment and Setup } & 10\end{array}$

$\begin{array}{ll}\text { Startup Steps } & 12\end{array}$

$\begin{array}{ll}\text { Feed Sources and Characterizations } & 13\end{array}$

Aqueous Strip Solution $\quad 13$

DSS Simulant $\quad 13$

$\begin{array}{ll}\text { Solvent Batches } & 14\end{array}$

DISCUSSION OF RESULTS 15

Correlation of Turbidity in SE with Measured Levels of Isopar® L 18

Results from Initial Tests of Carryover Reduction 19

$\begin{array}{ll}\text { Adjustment of } \mathrm{pH} & 19\end{array}$

Glass Fiber Filter Pad 19

$\begin{array}{ll}\text { Coalescer } & 20\end{array}$

Color of Organic Phase and Related Analyses $\quad 21$

Measurements of Modifier and Trioctylamine $\quad 21$

$\begin{array}{ll}\text { SUMMARY OF RESULTS } & 24\end{array}$

APPENDIX A: Test Plan for 4-Contactor Bank Operation in Support Of MCU Carryover Work 26

APPENDIX B: Organic Droplet Size Data Expressed as Volume Fractions 30

APPENDIX C: Optical Micrographs of Samples 31

$\begin{array}{ll}\text { REFERENCES } & 36\end{array}$ 


\section{LIST OF FIGURES}

Figure 1. Four-Contactor Bank and Supporting Equipment $\quad 11$

Figure 2. Flow Diagram for Contactor Bank and Supporting Equipment 12

Figure 3. Optical Micrograph of Sample 12 at 1000X 18

Figure 4. Relationship between Sample Turbidity and Reported Isopar® L Mass Concentration

Figure 5. Comparisons of Clarity before (left) and after Glass Fiber 20

Figure 6. Color Comparison in Organic Decanter versus Unused Parsons-SRS Solvent 22

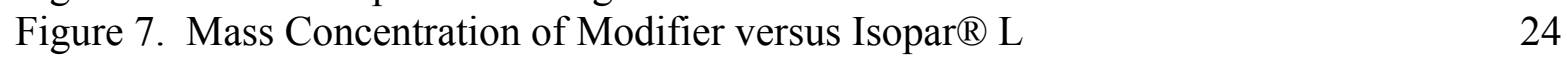

Figure 8. Optical Micrograph of Sample 4, 500X 31

Figure 9. Optical Micrograph of Sample 5, 500X 31

Figure 10. Optical Micrograph of Sample 6, 500X 32

Figure 11. Optical Micrograph of Sample 7, 500X 32

Figure 12. Optical Micrograph of Sample 8, 500X 33

Figure 13. Optical Micrograph of Sample 11, 500X 33

Figure 14. Optical Micrograph of Sample 12 at 500X 34

Figure 15. Optical Micrograph of Sample 15 at 500 X 34

Figure 16. Optical Micrograph of Sample 16 at 500 X 35

\section{LIST OF TABLES}

Table 1. Summary of Organic Entrainment Measurements $\quad 6$

Table 2. Record of Equipment used in the Four-Contactor Bank 10

Table 3. Formulation of DSS Simulant 14

Table 4. Nominal Flow Rates and Decanter Volumes 15

Table 5. Experimental Results 16

Table 6. Modifier and Related Isopar® L Levels in the Samples 23

Table 7. Nominal Conditions for Salt Solution and Strip Solution Operations 28

Table 8. Sample Timing 28 


\section{INTRODUCTION}

The Modular Caustic-Side Solvent Extraction (CSSX) Unit (MCU) and the Salt Waste Processing Facility (SWPF) are designed to remove radioactive cesium from Savannah River Site high-level wastes. The project conceptual designs limit organic solvent entrainment in these streams to approximately $50 \mathrm{ppm}$ which was thought adequate to protect downstream processes and limit costs for solvent replacement. However, preliminary evaluation of solvent carryover impacts identified much lower limits for the Defense Waste Processing Facility (DWPF), Saltstone Production Facility (SPF), and Tank 50.

The MCU project issued a project early warning identifying reductions in the carry-over acceptance limits for downstream facilities. ${ }^{1}$ Closure Business Unit (CBU) management chartered the CSSX Solvent Integration Team (CSIT) with Glynn Dyer as team leader to evaluate the situation and propose integrated solutions that consider impacts to all of the affected facilities. ${ }^{2}$ This report covers the experimental work done with a bank of four 2-cm centrifugal contactors to address organic carryover issues. In addition a report on work with a Costner Industries of Nevada Corporation (CINC) V-5 contactor in the Engineering Development Laboratory (EDL) is also being issued. ${ }^{3}$

Past work at Savannah River National Laboratory (SRNL) measured organic carryover during CSSX flowsheet demonstrations with 2 -cm centrifugal contactors and actual tank waste., ${ }^{4,6,7}$ Subsequently, Argonne National Laboratory (ANL) used 4-cm centrifugal contactors and simulated solutions to study the effects of contactor conditions on organic carryover. ${ }^{8,9} \mathrm{~A}$ summary of results for strip solution and decontaminated salt solution (DSS) is in Table 1.

Table 1. Summary of Organic Entrainment Measurements

\begin{tabular}{|l|c|c|}
\hline $\begin{array}{l}\text { Report documenting } \\
\text { Campaign }\end{array}$ & $\begin{array}{c}\text { Type of } \\
\text { Aqueous } \\
\text { Output }\end{array}$ & $\begin{array}{c}\text { Organic Content from Aqueous } \\
\text { Decanter expressed as ppm by } \\
\text { volume }\end{array}$ \\
\hline WSRC-TR-2001-00372 & DSS & 350 in final 12 hours \\
\hline & Strip & Less than 6 \\
\hline WSRC-TR-2002-00243, rev. 1 & DSS & 190 on average \\
\hline & Strip & 20 to 320 \\
\hline WSRC-TR-2002-00307 & DSS & 170 \\
\hline & Strip & 510 \\
\hline ANL-02/08 & DSS & 120 to 241 \\
\hline & Strip & 4 to 125 \\
\hline ANL-02/34 & DSS & 3 to 300 (see text) \\
\hline
\end{tabular}

The ANL-02/34 work found inconsistencies in the organic analyses leading to the large range of values shown in the table. Analyses based on the BoBCalix, modifier, and Isopar ${ }^{\circledR}$ L were noted to be inconsistent. Much of the inconsistency at that time was ascribed to possible evaporation of Isopar ${ }^{\circledR}$ L from the samples. 
ANL attempted to measure organic droplet sizes with a Coulter Counter and consistently found bimodal distributions from the machine. A very large peak generally across the 100200 micron range was found, and a small broad peak in the single-digit micron range was also reported. The large peak was also present in aqueous liquids that had not been contacted with an organic phase, indicating that particles outside of organic droplets were present in the feed.

\section{Sub-team A Membership}

The following personnel comprised Sub-team A.

Charles A. Nash, SRNL, team leader

Harry D. Harmon, PNNL

Patricia C. Suggs, DOE

Ronnye A. Eubanks, CBU

Michael A. Norato, CBU

Robert A. Pierce, SRNL

Darrel D. Walker, SRNL

\section{EXPERIMENTAL APPROACH}

\section{Work Specification, Safety, and Quality Level}

This experimental task was specified through CSIT and Sub-team A meetings. This is sufficient for specification of non-baseline research and development (R\&D). ${ }^{10}$ The resultant work scope statement is provided in Appendix A. The experimental effort is non-baseline scoping work. Experimental steps and results are recorded in a laboratory notebook. ${ }^{11}$ Safety and environmental issues were covered by following the SRNL Conduct of R\&D Manual. ${ }^{12,13}$

\section{Analytical Services}

Quantification of minimum organic droplet size, the droplet size distribution, and the total organic content from the aqueous strip and salt waste streams required advancement of analytical techniques. Sub-team A thus met with key personnel to establish the needed services. Results are summarized in the four following sections.

\section{Particle Size Distribution (PSD) for Droplet Size}

Successful designs of some organic removal options for aqueous streams depend upon accurate knowledge of organic droplet size. Design of coalescers and centrifuges are examples. Wilson Smith of the Analytical Development Section (ADS) performed initial work on microscopic glass beads and the SRNL Microtrac $\AA$ S3000 in January, discovering that the instrument would likely succeed with the similar transparent system of organic droplets in aqueous phases. ${ }^{14}$ The instrument requires particle-free pre-filtered liquid matrix (300 mL per sample), estimates of liquid and transparent bead indices of refraction, and a 
setting to "transparent" systems. The current work proceeded to use the Microtrac ${ }^{\circledR}$ S3000 with plans to verify reasonableness of results by optical microscopy.

Sample age for this analysis was considered especially important because the larger organic droplets rise to the top of samples with time and coalesce. Aqueous strip solution samples were analyzed at a target time of 2 hours after sampling commencement, this being less than the 500 minute residence time for the MCU strip decanter. Simulated DSS samples were analyzed 1 hour after sampling commencement, this also being shorter than the 170 minute residence time for the MCU DSS decanter. The goal was to remove the readily-decanted second phase so that this work could focus on the more troublesome and persistent organic dispersion.

While ADS uses a specific procedure for operation of the Microtrac ${ }^{\circledR}$ S3000, ${ }^{15}$ a general list of steps is given here:

1. The instrument (S3000 with separate circulating control unit) is charged with approximately $300 \mathrm{~mL}$ of matrix-matched aqueous liquid after routine flushing of the machine are performed.

2. The $\mathrm{S} 3000$ provides a baseline reading of particles in the liquid. The count rate must be less than a machine-determined limit to indicate that the instrument and fluid are clean and free of air bubbles.

3. Normally a few $\mathrm{mL}$ of sample is introduced into the circulating stream. Particles in the sample will immediately boost the count rate. Further sample is added to adjust the count rate to a new level specified by S3000 operating procedure.

4. Number-weighted count scans are recorded and averaged.

5. The S3000 calculates volume-weighted particle distribution from the numberweighted data.

6. Results for the sample are printed in the form of tabulated percentages of particles less than machine-established bin sizes, along with a bar graph of the levels in each bin.

\section{Optical Microscopy}

Optical microscopy was included in this work because the Microtrac ${ }^{\circledR}$ S3000 was recognized to have a major limitation: it does not distinguish between spherical organic droplets and foreign non-spherical particles. Optical micrographs readily identify whether organic droplets are actually present in an aqueous phase. They also provide general estimates of droplet size. The micrographs allow identification of precipitates, air bubbles, or other foreign materials if present. Organic droplets are identified by their round, transparent, and refractive appearance. Air bubbles, while round, appear very dark because of their much lower refractive index relative to aqueous liquid phases. Foreign materials would be identified primarily by nonspherical shapes.

Samples were analyzed at the same time that Microtrac ${ }^{\circledR}$ portions of the same samples were examined. 
Zane Nelson and Cindy Foreman took photo micrographs on a Zeiss Axiovert ${ }^{\mathrm{TM}} 100 \mathrm{~A}$ metallograph. The NIST registered number for the stage micrometer that was used is 474027 . Low reflectivity of the samples resulted in very little contrast in the images. Use of Differential Interference Contrast (DIC) and Normarksi lighting techniques were employed. Samples were "mounted" on thin microscope slides. Cover slides were used when they were found to improve imaging of droplets.

\section{Organic content}

Sub-team A met with Stephen Crump, John Young, and Tom White of ADS to determine the best means of measuring Isopar ${ }^{\circledR} L$ levels in organic dispersions in aqueous samples. ADS recommended semivolatile organic analysis (SVOA) by gas chromatography-mass spectroscopy (GC-MS) for determination of Isopar ${ }^{\circledR}$ L. Determination of the Isopar ${ }^{\circledR}$ L component was considered paramount because (1) it is the major component of the solvent, and (2) it is the only component that provides a credible flammability concern because of its flash point of approximately $66^{\circ} \mathrm{C}$ in the pure state. The BoBCalix, Cs-7SB modifier, and trioctylamine (TOA) are much less volatile by comparison. In addition the BoBCalix and TOA are present in the solvent at levels of $0.007 \mathrm{M}$ or less. TOA is semivolatile and can be determined by SVOA GC-MS methods, but is nevertheless a minor component of the solvent mixture.

WPT personnel sealed samples of organic solvent dispersed in aqueous solutions in glass vials with Teflon ${ }^{\circledR}$ lined caps to avoid evaporation of the volatile organic. Personnel filled the vials nearly full to minimize loses to the vapor space of the vials.

ADS personnel prepared SVOA samples by extracting organic content into the solvent methylene chloride by the following general steps. All of the sample was placed in a separatory funnel after weighing the sample in its vial. Three sub-portions of methylene chloride were applied in sequence to the sample vial and cap to ensure the capture of all organic in the sample as submitted. The clean sample vial and cap were weighed to allow determination of sample mass. Personnel contacted each sub-portion of methylene chloride with the sample itself in the separatory funnel. The three methylene chloride extracts were collected in one container and concentrated by nitrogen evaporation at room temperature.

The concentrated methylene chloride extract was analyzed by GC-MS. Analytical separations occurred on an Agilent 6890 gas chromatograph equipped with a $30 \mathrm{~m}$ DB-XLB column. The column had a diameter of $0.18 \mathrm{~mm}$ and a film thickness of $0.25 \mathrm{um}$. Quantification used an Agilent 5973 mass selective detector. Personnel confirmed the mass spectrometer tuning within 24 hours prior to each measurement using perfluorotributylamine. The accuracy claimed for the Isopar ${ }^{\circledR}$ L determinations -based on standards - is $\pm 10 \%$. Analyses focused primarily on Isopar ${ }^{\circledR}$ L content - i.e., the flammable organic constituent - but personnel also analyzed selected samples for TOA and modifier. 


\section{Turbidity}

Turbidity measurements during rig operation helped determine steady state. Personnel also measured turbidity at times concurrent to those of the Microtrac $₫$ and metallograph (microscope) analyses. An Orbeco-Hellige Model 965 turbidimeter was calibrated and operated using a WPT section procedure. ${ }^{16}$

\section{Experimental Equipment and Setup}

A bank of ANL 2-cm centrifugal contactors, spares from past work, ${ }^{17}$ was set up in laboratory B114 along with glass decanters. Table 2 shows the equipment numbers. Figure 1 is a photograph of the equipment and Figure 2 is a diagram of the flows. Physical dimensions of the contactors are specified on ANL print number CMT-E1265 titled "2-cm Contactor" and dated January 6, 1994. To improve stage efficiency, the hole at the bottom of each rotor was modified to make the rotor partially pumping. ${ }^{18}$ Bottom holes were all 0.42 inches in diameter. Motor shafts were extended from previous designs to allow visual verification of rotation. ${ }^{19}$ All contactors in this work used aqueous weirs designed for strip operation. The aqueous weirs had a diameter of 0.481 to 0.482 inch.

Spare glass decanters from the reference 17 work were used for these experiments. Decanters D-1 and D-3 for aqueous streams had sidearms to deliver decanted product. They also had separate sidearms with stopcocks for removal of organic solvent layers that would be captured in the decanter. The organic decanter D-2 had an internal underflow weir and a sidearm for delivery of decanted organic solvent. It had a bottom drain with stopcock for removal of any aqueous phase that settled out.

Table 2. Record of Equipment used in the Four-Contactor Bank

\begin{tabular}{|l|c|c|}
\hline & Body Marking & Rotor \\
\hline Leftmost contactor & $45 \mathrm{C}$ & $\mathrm{C} 38$ \\
\hline & $46 \mathrm{C}$ & $08 \mathrm{C}$ \\
\hline & $47 \mathrm{C}$ & $14 \mathrm{C}$ \\
\hline Rightmost contactor & $48 \mathrm{C}$ & $21 \mathrm{C}$ \\
\hline Strip decanter & D-3 & -- \\
\hline Organic decanter & D-2 & -- \\
\hline DSS decanter & D-1 & -- \\
\hline
\end{tabular}


Figure 1. Four-Contactor Bank and Supporting Equipment

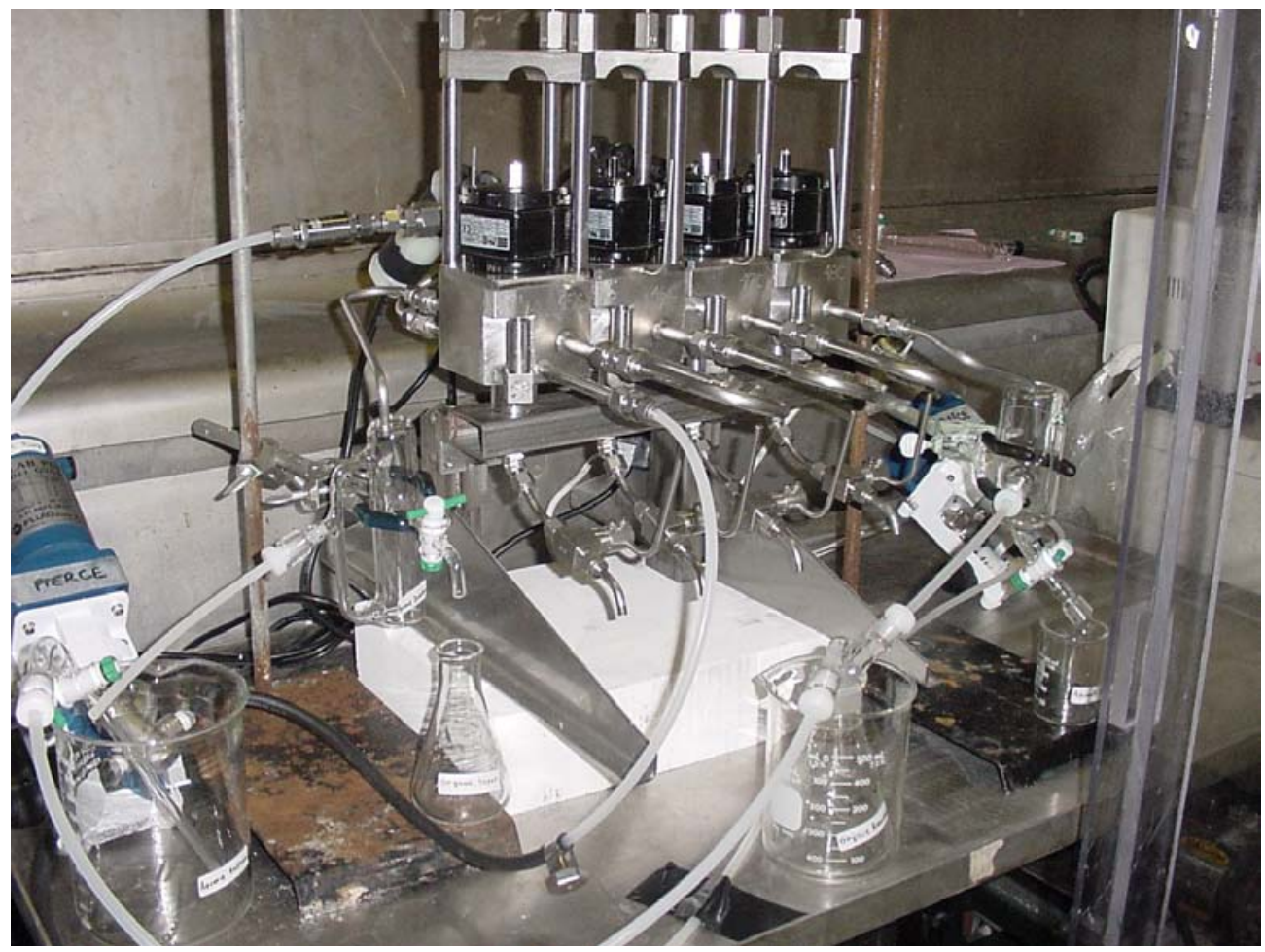


Figure 2. Flow Diagram for Contactor Bank and Supporting Equipment

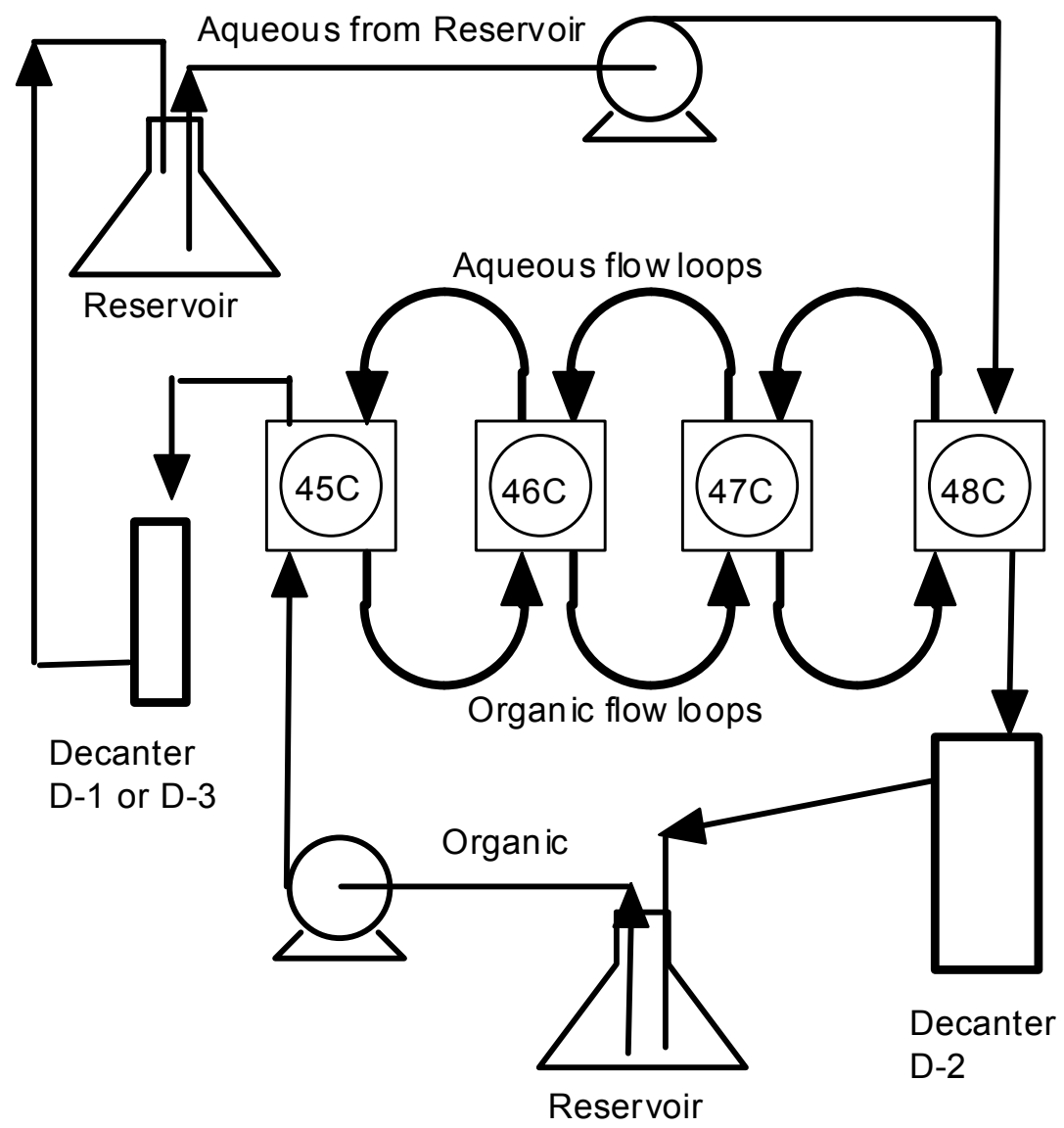

\section{Startup Steps}

Personnel took the following steps to prepare for and start an experiment. The rig was initially empty because previous shutdowns included work to drain and measure contents of each contactor.

1. Aqueous material, whether strip or DSS simulant, was always prefiltered through 0.45 micron Nalgene filters before use.

2. Pumps were calibrated to desired flow rates by timing liquid flow into graduated cylinders. Pump speeds were adjusted by changing controller settings, though the higher flow pump used for DSS simulant was adjusted by changing the pump head angle.

3. Approximately $300 \mathrm{~mL}$ of the solvent were placed in the solvent reservoir, and 300-600 $\mathrm{mL}$ of aqueous were placed into the aqueous reservoir.

4. Turn on the circulating water bath that controls rig temperature. A thermocouple measured in an insulated section about the contactors. In addition a thermometer was used to determine temperature of organic flowing into the organic decanter. 
5. Start nitrogen flow to the contactors. We used a low flow indicator (rotameter) to verify a low flow of filtered house nitrogen that was found to not disturb the contactor operation. The nitrogen flow is used to mitigate risks of acid corrosion to the motors.

6. Draw approximately $100 \mathrm{~mL}$ from the aqueous reservoir and pour $20-25 \mathrm{~mL}$ slowly into the standpipe of each contactor. This method reduced startup time compared to waiting for filling at the nominal $2.5 \mathrm{~mL} / \mathrm{min}$ flow rate from the strip effluent pump.

7. Turn contactors on, and then also turn on the aqueous pump.

8. Once aqueous flow through the contactor bank is verified visually by somewhat steady flow going into the aqueous decanter, the organic pump is turned on.

9. Initial approach to steady operation starts when solvent begins to flow out the rightmost contactor and into the organic decanter. This takes about 20 minutes for strip operation at nominal flow rates. During this time much solvent would be discharged by the leftmost contactor into the aqueous decanter.

10. The rig is considered to be running steadily when there are aqueous and organic flows back to respective decanters and when temperatures are in the desired ranges. For strip operation both the contactor block and the organic output streams are both to be $33+/ 3{ }^{\circ} \mathrm{C}$. For simulated DSS operation the temperature range is $23+/-3{ }^{\circ} \mathrm{C}$.

11. Samples are taken after the rig has operated for at least three aqueous decanter residence times. Sample collection commences when a $125-\mathrm{mL}$ separatory funnel is positioned to capture the liquid flowing out of the aqueous decanter. The one or two hour sample clock is considered to start when collection begins.

12. Sample handling is given in Appendix A. Aqueous contactor samples were aged for 1 hour (DSS) or 2 hours (SE) before droplet size, optical microscopy, and turbidity were measured. The aging was intended to allow removal of the larger droplets from the samples so that the most troublesome small droplets could be quantified.

\section{Feed Sources and Characterizations}

\section{Aqueous Strip Solution}

Aqueous strip solution was prepared by spiking a measured amount of nitric acid at known strength into deionized (DI) water to give a $0.001 \mathrm{M}$ solution ( $\mathrm{pH} 3$ ). All of this liquid was filtered through 0.45 micron Nalgene ${ }^{\mathrm{TM}}$ laboratory filters before use.

\section{DSS Simulant}

Caustic salt simulant filtrate from past work was used. ${ }^{20}$ The recipe, Table 3 , is that commonly used for work with monosodium titanate. ${ }^{21}$ It was used after filtration through a 0.45 micron Nalgene ${ }^{\mathrm{TM}}$ laboratory filter. The concentration of some elements was verified by inductively coupled-plasma emission spectroscopy (ICP-ES) to be the target values within the nominal $10 \%$ analytical error of this measurement. 
WSRC-TR-2005-00182, rev. 0

Page 14 of 37

Table 3. Formulation of DSS Simulant

\begin{tabular}{|l|c|c|}
\hline Component & $\begin{array}{c}\text { Target } \\
\text { Molarity }\end{array}$ & $\begin{array}{c}\text { Measured } \\
\text { Molarity }\end{array}$ \\
\hline Free hydroxide & 1.33 & \\
\hline Nitrate & 2.60 & 0.41 \\
\hline Aluminum (as aluminate) & 0.429 & \\
\hline Nitrite & 0.134 & 0.51 \\
\hline Sulfate & 0.521 & \\
\hline Carbonate & 0.026 & 5.4 \\
\hline Total Sodium & 5.60 & \\
\hline
\end{tabular}

\section{Solvent Batches}

An archived solvent batch, adjusted to return concentrations within process specifications, was used for the first set of DSS/organic contacts. SRNL personnel reworked a portion of the original baseline CSSX solvent to obtain the optimized composition (0.007 M BoBCalix, 0.75 $M$ modifier, $0.003 \mathrm{M}$ TOA).

Personnel combined $700 \mathrm{~mL}$ of solvent (i.e., archived batch of solvent; ORNL Lot No. PVB B000894-31W, 11/29/00; 0.010 M BoBCalix, 0.500 M Cs-7SB, and 0.0010 M TOA) with $800 \mathrm{~mL}$ of (ORNL Lot No. B000894-6DM 3/27/01; $0.50 \mathrm{M}$ modifier) modifier solution. The materials were measured using calibrated glassware (B-107-1, B-107-7) into a 2L glass flask. After personnel mixed the components, they rotary evaporated the 1.5 liters of solution to a final volume of 1 liter.

To this 1 liter of solution, researchers added $1.063 \mathrm{~mL}$ of TOA. This provided a final TOA concentration of $0.003 \mathrm{M}$. The solution was thoroughly mixed before sampling.

Density of the reworked solvent was analyzed with the following results. Personnel used a calibrated $5 \mathrm{~mL}$ volumetric flask to measure the density of the reworked solvent, giving an average value of $0.8488 \mathrm{~g} / \mathrm{mL}$ at $23.3{ }^{\circ} \mathrm{C}$. The standard deviation of error was 0.10 percent $(1 / 1000)$ of the average value. An SVOA analysis of the material gave a TOA result of 1200 $\mathrm{mg} / \mathrm{L}$, or $0.0034 \mathrm{M}$.

The last DSS/organic contact in this test series used solvent loaned by Parsons-SRS and adjusted to within process specifications by SRNL. The material had previously been processed through a pilot test program for the SWPF by Parsons-SRS before receipt at SRNL. The solvent was filtered and partly distilled for removal of excess Isopar ${ }^{\circledR}$ L so that its required density was restored. The solvent received for this work was clear but had a strong yellow color. Details of the processing of the solvent are found in another report. ${ }^{3}$ 


\section{DISCUSSION OF RESULTS}

The analytical tools developed for this work successfully obtained the proposed particle size distributions, dispersed solvent concentrations, optical micrographs, and turbidity of aqueous contactor samples.

Table 4 displays the nominal flow rates for 2 -cm centrifugal contactor operation. Flow rates and decanter equipment specifications came from the work documented in prior process demonstrations. ${ }^{4}$

Table 4. Nominal Flow Rates and Decanter Volumes

\begin{tabular}{|l|l|l|l|l|}
\hline Decanter & Stream & Flow Rate & $\begin{array}{l}\text { Decanter } \\
\text { Volume }\end{array}$ & $\begin{array}{l}\text { Residence } \\
\text { Time }\end{array}$ \\
\hline D-1 & DSS & $\begin{array}{l}37.5 \mathrm{~mL} / \mathrm{min} \\
\text { (aqueous) }\end{array}$ & $\begin{array}{l}111 \mathrm{~mL} \\
\text { (aqueous) }\end{array}$ & $3.0 \mathrm{~min}$ \\
\hline D-2 & $\begin{array}{l}\text { Solvent } \\
\text { recycle }\end{array}$ & $\begin{array}{l}12.5 \mathrm{~mL} / \mathrm{min} \\
\text { (organic) }\end{array}$ & $\begin{array}{l}65 \mathrm{~mL} \\
\text { (organic) }\end{array}$ & $5.0 \mathrm{~min}$ \\
\hline D-3 & $\begin{array}{l}\text { Strip effluent } \\
\text { (SE) }\end{array}$ & $\begin{array}{l}2.5 \mathrm{~mL} / \mathrm{min} \\
\text { (aqueous) }\end{array}$ & $\begin{array}{l}37 \mathrm{~mL} \\
\text { (aqueous) }\end{array}$ & $12.0 \mathrm{~min}$ \\
\hline D-4* & Wash raffinate & $\begin{array}{l}2.5 \mathrm{~mL} / \mathrm{min} \\
\text { (aqueous) }\end{array}$ & $\begin{array}{l}75 \mathrm{~mL} \\
\text { (aqueous) }\end{array}$ & $25.0 \mathrm{~min}$ \\
\hline
\end{tabular}

* Not used in the current work

Table 5 displays all but the optical micrograph results. Sample numbers were assigned after the test program for the sake of the current discussion. Nominal flow is defined in Table 4 . Note that the O:A flow ratio is 3 for DSS and 0.2 for SE. "Special treatment" refers to attempts to reduce SE organic content in some experiments. The balance of experiments either varied type of aqueous feed, flow rates from nominal conditions, or else examined the behavior of the Parsons-SRS solvent.

Droplet size distribution data from selected bins is provided in Appendix B. The volume fraction of organic droplets above the given bin size is given as a cumulative number. No droplets were found to have diameters below the 0.486 micron level in any sample.

Micrographs of aqueous samples are in Appendix C. Images are not available for every sample. Some samples provided too much difficulty to provide good images. For example, organic droplets could not be found in Sample 14. Ease of obtaining good images was not predictable. 
Table 5. Experimental Results

\begin{tabular}{|c|c|c|c|c|c|c|c|c|c|c|c|c|}
\hline $\begin{array}{l}\text { Sample } \\
\text { Number }\end{array}$ & $\begin{array}{c}\text { Aqu- } \\
\text { eous } \\
\text { Phase }\end{array}$ & $\begin{array}{l}\text { Organic } \\
\text { Solvent }\end{array}$ & $\begin{array}{c}\text { Percent } \\
\text { Nominal } \\
\text { Flow } \\
\end{array}$ & $\begin{array}{c}\text { Special } \\
\text { Treat- } \\
\text { ment }\end{array}$ & $\begin{array}{l}\text { Test } \\
\text { Date }\end{array}$ & $\begin{array}{c}\text { Isopar }{ }^{\circledR} \\
\text { L, ppm }\end{array}$ & $\begin{array}{r}\text { ppm I } \\
\text { less tha }\end{array}$ & $\begin{array}{r}\text { opar } \AA \\
\text { indic } \\
\text { (ppI }\end{array}$ & $\begin{array}{l}\text { cont: } \\
\text { ced dia } \\
\text { are ac }\end{array}$ & $\begin{array}{l}\text { ned in } \\
\text { neter in } \\
\text { litive) }\end{array}$ & $\begin{array}{l}\text { oplets } \\
\text { nicrons }\end{array}$ & $\begin{array}{c}\text { Turbidity, } \\
\text { NTU }\end{array}$ \\
\hline & & & & & & & $5.5 \mu$ & $7.8 \mu$ & 11. $\mu$ & $13.1 \mu$ & $18.5 \mu$ & \\
\hline 1 & Strip & archive & 100 & & $3 / 16 / 05$ & 7.9 & No Data & & & & & 12.1 \\
\hline 2 & Strip & archive & 100 & & $3 / 17 / 05$ & 42 & 15 & 24 & 32 & 38 & 42 & 76 \\
\hline 3 & Strip & archive & 100 & & $3 / 17 / 05$ & 29 & No Data & & & & & \\
\hline 4 & Strip & archive & 50 & & $3 / 18 / 05$ & 43 & 20 & 28 & 40 & 42 & 43 & 79 \\
\hline 5 & Strip & archive & 100 & & $3 / 21 / 05$ & 79 & 36 & 48 & 69 & 75 & 79 & 103 \\
\hline 6 & Strip & archive & 100 & & $3 / 21 / 05$ & 91 & No Data & & & & & \\
\hline 7 & Strip & archive & 100 & $\mathrm{pH} 1$ & $3 / 22 / 05$ & 33 & 31 & 33 & 33 & 33 & 33 & 34.5 \\
\hline 8 & Strip & archive & 100 & $\mathrm{pH} 11$ & $3 / 22 / 05$ & 63 & 25 & 32 & 53 & 60 & 63 & 92.6 \\
\hline 9 & Strip & archive & 100 & $\mathrm{pH} 1$ & $3 / 22 / 05$ & 26 & 16 & 24 & 26 & 26 & 26 & 98.5 \\
\hline 10 & Strip & archive & 100 & $\mathrm{pH} 11$ & $3 / 22 / 05$ & 21 & 18 & 21 & 21 & 21 & 21 & 20.8 \\
\hline 11 & Strip & archive & 100 & & $3 / 22 / 05$ & 95 & 18 & 42 & 59 & 89 & 95 & 51.7 \\
\hline 12 & Strip & archive & 75 & & $3 / 23 / 05$ & 27 & 17 & 20 & 24 & 26 & 27 & 41.9 \\
\hline 13 & Strip & archive & 75 & & $3 / 23 / 05$ & 29 & 15 & 20 & 27 & 28 & 29 & 47.6 \\
\hline 14 & Strip & archive & 75 & Glass & $3 / 23 / 05$ & $5.9 * *$ & No Data & & & & & 7.3 \\
\hline & & & & fiber & & & & & & & & \\
\hline 15 & DSS & archive & 50 & & $3 / 24 / 05$ & 16 & $13 *$ & 16 & 16 & 16 & 16 & 6 \\
\hline 16 & DSS & archive & 50 & & $3 / 24 / 05$ & 19 & $15 *$ & 19 & 19 & 19 & 19 & 5.2 \\
\hline 17 & Strip & Parsons & 100 & & $3 / 25 / 05$ & 11 & $10 *$ & 11 & 11 & 11 & 11 & 27.6 \\
\hline 18 & Strip & Parsons & 100 & & $3 / 25 / 05$ & 3.5 & $3 *$ & 4 & 4 & 4 & 4 & 12.1 \\
\hline 19 & DSS & archive & 50 & & $3 / 31 / 05$ & $7.9 * * *$ & $7 *$ & 8 & 8 & 8 & 8 & 4.5 \\
\hline 20 & DSS & archive & 50 & Coalesce & $3 / 31 / 05$ & $5.8 * * *$ & $3 *$ & 6 & 6 & 6 & 6 & 14. \\
\hline
\end{tabular}


Notes on Table 5:

"Nominal" flow rates are defined in Table 4.

“Isopar® L, ppm” defines ppm on a mass basis - as mass per mass of dispersion - as determined by SVOA.

"Parsons" organic solvent refers to recovered Parsons-SRS solvent loaned to SRNL.

"No Data" for Microtrac ${ }^{\circledR}$ droplet size indicates that the sample had too few droplets to report any PSD, or that a Microtrac ${ }^{\circledR}$ measurement of a duplicated sample was not made. Only one Microtrac ${ }^{\circledR}$ measurement was made while duplicate SVOA measurements were made on the 3/17/05 and 3/21/05 samples.

* Microtrac ${ }^{\circledR}$ signal strength for data in indicated rows is borderline low, but a droplet size distribution was acquired and its product with Isopar® L level is reported here.

**Data obtained on liquid after passage through a Millipore ${ }^{\mathrm{TM}}$ Glass Fiber Prefilter.

***SVOA of these samples was duplicated. Samples before passage through the coalescer element measured 5.9 and $9.8 \mathrm{mg} / \mathrm{L}$ Isopar ${ }^{\circledR} \mathrm{L}$ and the salt solution measured 5.6 and $6.0 \mathrm{mg} / \mathrm{L}$ Isopar ${ }^{\circledR} \mathrm{L}$ after filtering through the material. 
Particles were judged to be organic droplets if they were round and transparent-looking. Sample 12 is a good example. A picture at highest magnification (1000X) is shown in Figure 3 . That sample provided better imaging conditions than other samples. Non-spherical particles were almost never seen, suggesting freedom from precipitates or particulate contamination.

Figure 3. Optical Micrograph of Sample 12 at 1000X

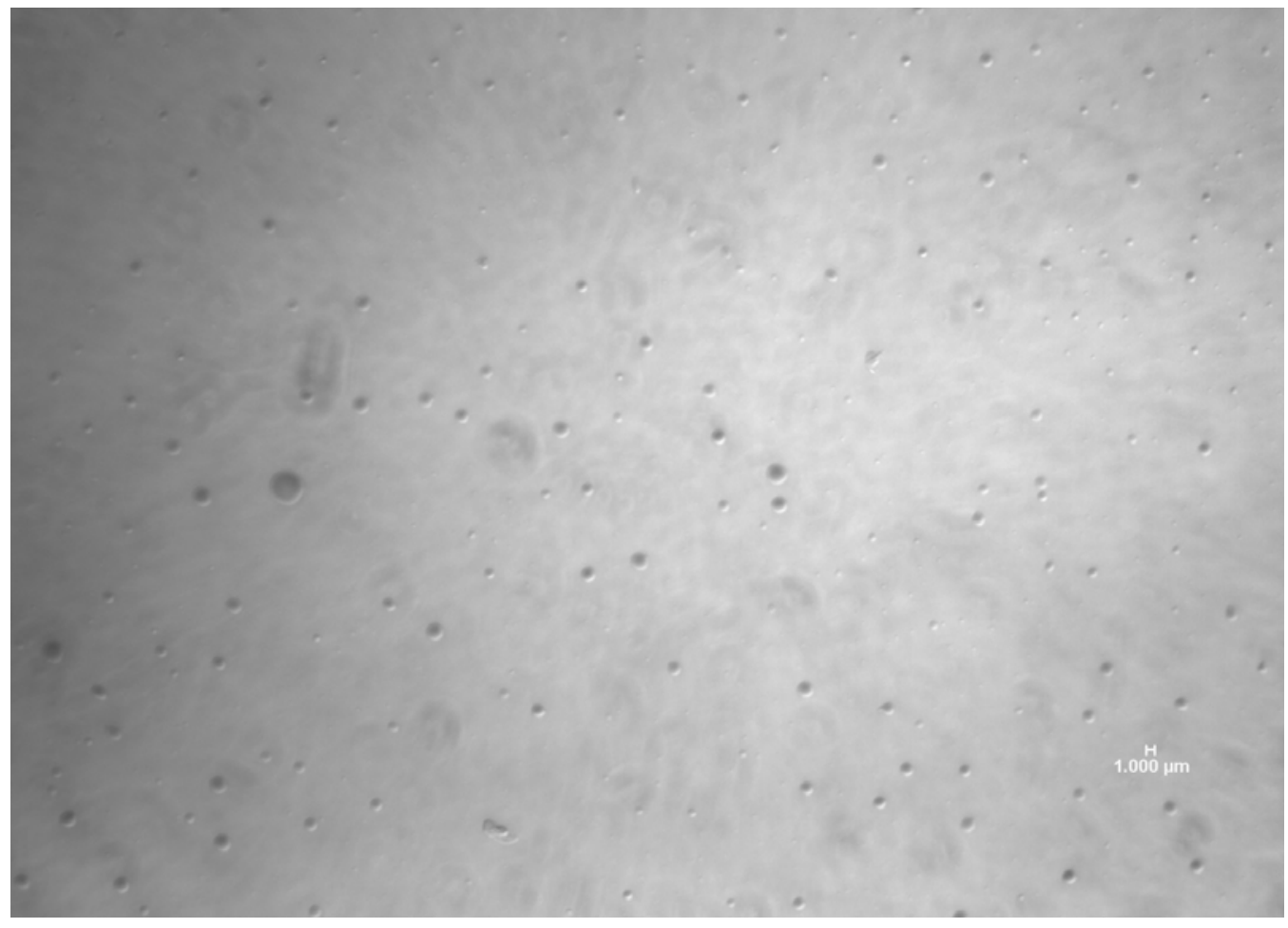

\section{Correlation of Turbidity in SE with Measured Levels of Isopar ${ }^{\circledR}$ L}

Figure 4 compares turbidity data from SE with reported mass levels of Isopar ${ }^{\circledR}$ L. The linear fit includes the origin because pure water has no turbidity. The data do appear roughly linear though two outlier points are present. This positive trend between turbidity and organic content would be expected since a higher concentration of organic droplets would increase the scattering of light. 
WSRC-TR-2005-00182, rev. 0

Page 19 of 37

Figure 4. Relationship between Sample Turbidity and Reported Isopar® L Mass Concentration

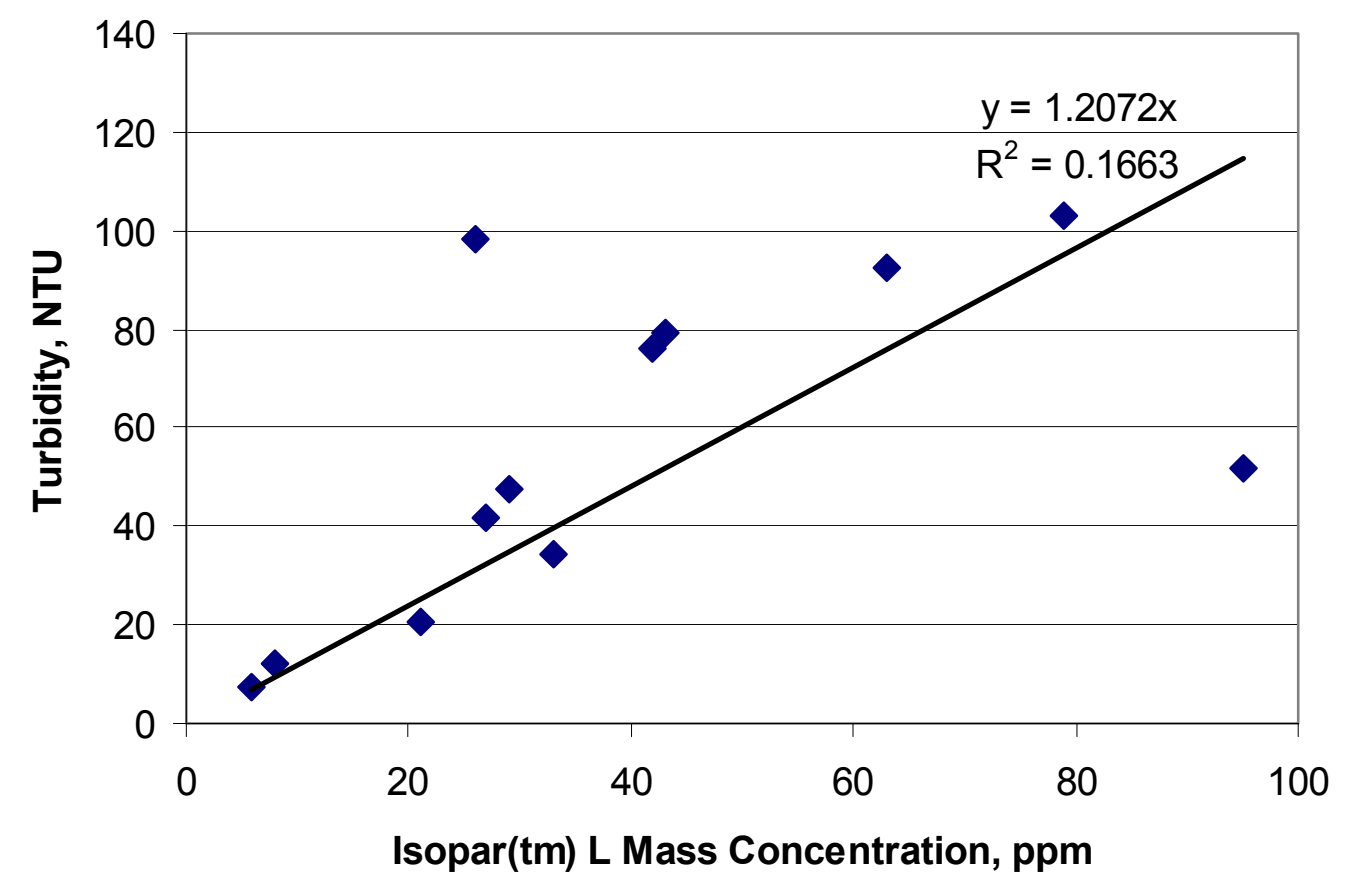

\section{Results from Initial Tests of Carryover Reduction}

\section{Adjustment of $\mathrm{pH}$}

Personnel $\mathrm{pH}$-adjusted samples of strip effluent to examine whether an adjustment of the stream by addition of practical volumes (e.g., dilution of a few volume percent) of acid or caustic would enhance separation of the entrained organic. Samples 7 through 10 shown in Table 5 were $\mathrm{pH}$-adjusted immediately after collection of the $50-\mathrm{mL}$ portions of aqueous decanter output completed. Personnel added $1 \mathrm{~mL}$ of $5 \mathrm{M}$ nitric acid to reduce $\mathrm{pH}$ to approximately 1 in each of Samples 7 and 9. They added $1 \mathrm{~mL}$ of $0.1 \mathrm{M} \mathrm{NaOH}$ to boost the $\mathrm{pH}$ to 11 in Samples 8 and 10. There was no visual or quantitative evidence of significant organic separation as a result of these adjustments. No reduction of Isopar ${ }^{\circledR}$ L content was apparent when the variation in nominal value is considered. Samples 1, 2, 3, 5, 6, and 11 came from runs of nominal conditions and show Isopar ${ }^{\circledR}$ L values from 8 to 95 ppm.

\section{Glass Fiber Filter Pad}

Sample 14 was aqueous material similar to Samples 12 and 13, except that it had passed though a glass fiber filter pad before the measurements reported in Table 5 were made. This work used a Millipore ${ }^{\mathrm{TM}}$ Glass Fiber Prefilter, catalog number APFF09050, rated at 0.7 micron. The filter material was made of very fine glass fiber and was approximately $3 / 4 \mathrm{~mm}$ thick. Figure 5 shows the significant difference in clarity - the hazy sample on the left was not filtered, and the product on the right had passed through filter medium. Slow manual 
addition limited the pressure driving force through the filter to less than 0.25 inch of water column at all times. The filter pad shown produced about $1 \mathrm{~mL} / \mathrm{min}$ of clarified liquid under this condition.

Figure 5. Comparisons of Clarity before (left) and after Glass Fiber Filtration

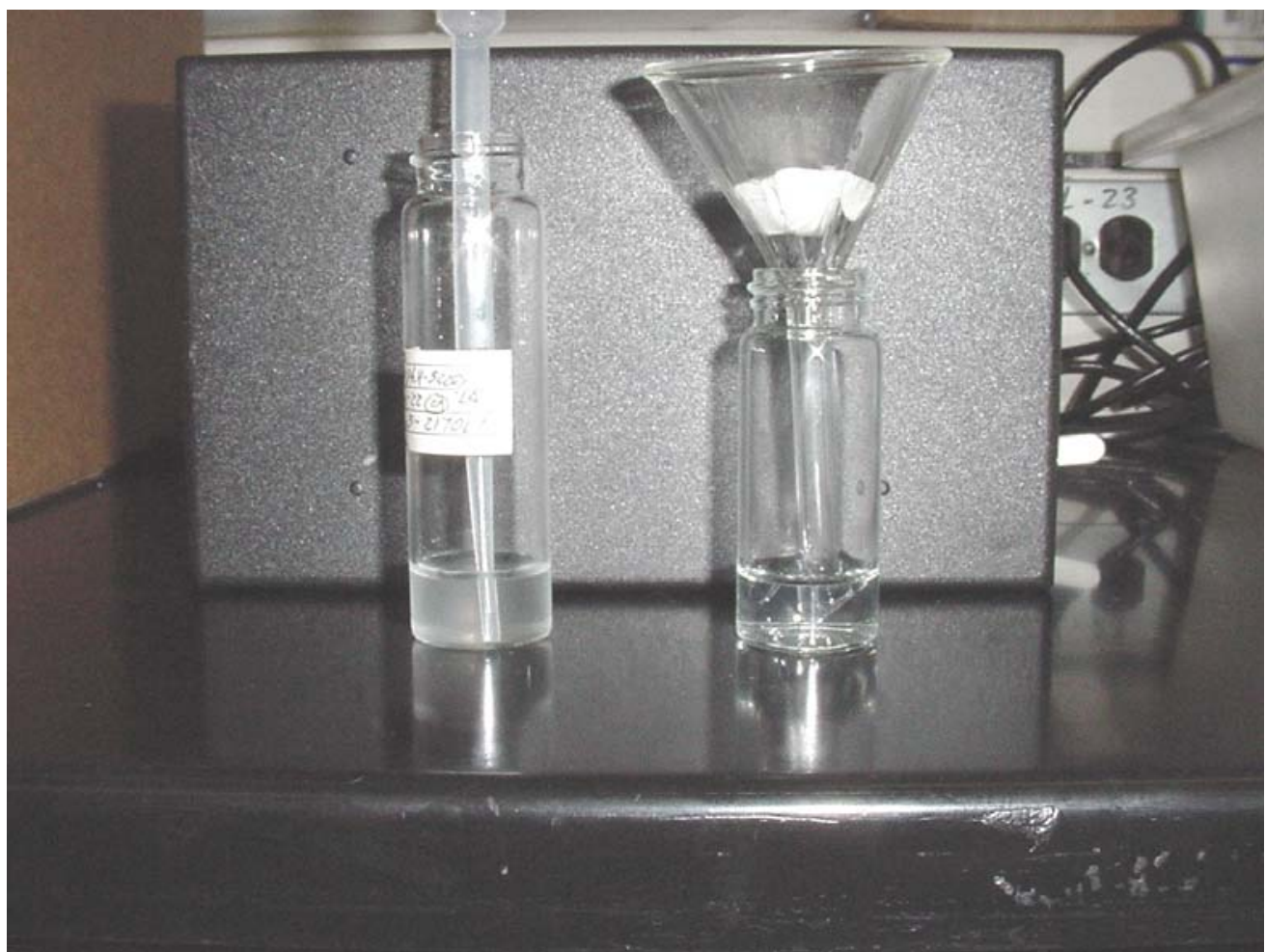

\section{Coalescer}

The experiment on March 31, 2005 produced fresh DSS/organic dispersion from the

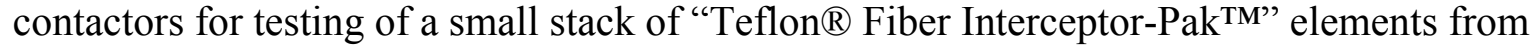
ACS Separations, Inc. The stack was about two inches long. Table 5 shows that there was a small reduction in organic (Sample 19 versus 20), though it is unclear whether the coalescer stack was the primary cause of this. Sample handling and exposure to new equipment may have also removed some material. Coalescer stack performance appeared to be mediocre in this test. Turbidity increased, possibly caused by fines contributed by the coalescer elements. A small but not thorough flush of the stack elements had been performed before the test. Some dark fines similar in color to the Teflon ${ }^{\circledR}$ elements were noticed in handling and using the coalescer material. 


\section{Color of Organic Phase and Related Analyses}

This section summarizes observations of solvent color. The archive batch of solvent was almost colorless and clear as provided. The portion used for the strip contact testing exhibited no visible color changes during the bulk of testing that produced Samples 1 to 14 .

Changing the aqueous phase from strip to DSS simulant produced a noticeable increase in yellow color of the solvent when the 2 -cm contactor rig started. The change of aqueous phase included (1) draining all contactors, the aqueous reservoir, and the aqueous decanter of all strip solution, (2) recovering any bulk solvent by pouring it slowly through the organic decanter by hand and removing the last strip solution from the decanter bottom drain, (3) replacing Decanter D-3 with a Decanter D-1, and (4) filling the aqueous reservoir with DSS simulant. The yellow color in this case did not approach the intensity of color of the ParsonsSRS solvent.

Parsons-SRS solvent had an intense yellow color at the start of testing. A notable reduction in the color occurred when it was contacted with fresh aqueous strip solution. The test produced Samples 17 and 18. The primary objective of this test was to investigate whether the solvent physical properties may have contributed to an emulsification upset that occurred with the use of a CINC V-5 contactor in the EDL. (See Ref. 3 for a full discussion.) Figure 6 clearly shows the reduction in yellow color with strip contact. The organic decanter on the left holds solvent that contacted aqueous strip solution. The bottle on the right holds solvent as received. 


\section{Figure 6. Color Comparison in Organic Decanter versus Unused Parsons-SRS Solvent}

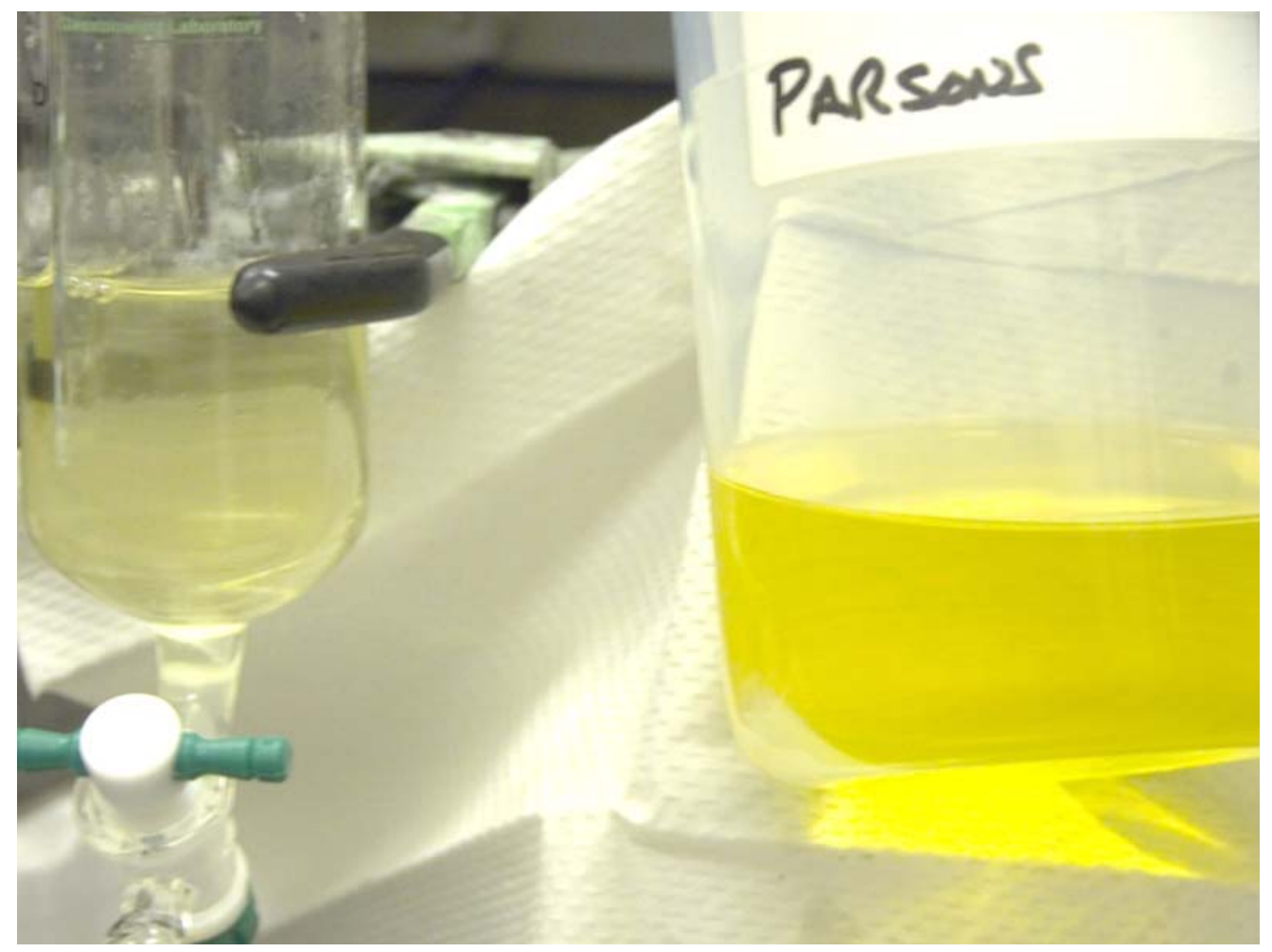

The density of Parsons-SRS solvent did not change on strip contact despite the color change. The yellow as-received solvent in Figure 6 had a density of $0.8516+/-0.0066 \mathrm{~g} / \mathrm{mL}$ and the strip-contacted solvent in the decanter and system had a density of $0.8526+/-0.0151 \mathrm{~g} / \mathrm{mL}$. Errors are one standard deviation. The temperature for these triplicate measurements was $22.5^{\circ} \mathrm{C}$.

\section{Measurements of Modifier and Trioctylamine}

While the original goal of SVOA analysis was to report Isopar ${ }^{\circledR}$ L levels in aqueous dispersions, the analysis also provided data on content of modifier and TOA. None of the samples from the 2-cm contactors contained TOA above detection limits. Table 6 shows modifier levels that were found in the samples. Solvent is expected to have mass ratios of Isopar ${ }^{\circledR}$ L:modifier:TOA of 554.2:239.0:1.0. Since the data show unexpectedly high modifier masses relative to Isopar ${ }^{\circledR}$ L masses an implied Isopar ${ }^{\circledR}$ L content is also provided. Implied Isopar ${ }^{\circledR}$ L levels were calculated by multiplying modifier values by the expected mass ratio of 554.2/239. 
Table 6. Modifier and Related Isopar ${ }^{\circledR}$ L Levels in the Samples

\begin{tabular}{|c|c|c|c|}
\hline $\begin{array}{c}\text { Sample } \\
\text { Number }\end{array}$ & $\begin{array}{c}\text { Isopar }{ }^{\circledR} \text { L Level, } \\
\text { ppm }\end{array}$ & $\begin{array}{c}\text { Modifier Level, } \\
\text { ppm }\end{array}$ & $\begin{array}{c}\text { Implied Isopar }{ }^{\circledR} \mathbf{L} \\
\text { Level, ppm }\end{array}$ \\
\hline 1 & 7.9 & 32 & 74 \\
\hline 2 & 42 & 71 & 165 \\
\hline 3 & 29 & 47 & 109 \\
\hline 4 & 43 & 100 & 232 \\
\hline 5 & 79 & 155 & 359 \\
\hline 6 & 91 & NA & NA \\
\hline 7 & 33 & 89 & 206 \\
\hline 8 & 63 & 150 & 348 \\
\hline 9 & 26 & 87 & 202 \\
\hline 10 & 21 & 91 & 211 \\
\hline 11 & 95 & 180 & 417 \\
\hline 12 & 27 & 93 & 216 \\
\hline 13 & 29 & 97 & 225 \\
\hline 14 & 5.9 & 42 & 97 \\
\hline 15 & 16 & 31 & 72 \\
\hline 16 & 19 & NA & NA \\
\hline 17 & 11 & 26 & 60 \\
\hline 18 & 3.5 & 20 & 46 \\
\hline 19 & $7.9^{*}$ & 30 & 70 \\
\hline 20 & $5.8^{*}$ & $38 *$ & 88 \\
\hline
\end{tabular}

* Average of duplicate measurements

Figure 7 is a linear fit of the data from experiments using SE and archive solvent. The y-axis intercept suggests a modifier content of $35 \mathrm{ppm}$ that is not associated with Isopar ${ }^{\circledR}$ L. This is not far from the expected 25 ppm solubility of modifier in SE. ${ }^{22}$ The slope of the line, however, is much higher than the 239/554.2 or 0.431 mass ratio that is expected for modifier: Isopar ${ }^{\circledR}$ L. The cause of this discrepancy is unknown. Loss of Isopar ${ }^{\circledR}$ L in samples or in analytical preparations of samples is a possible cause but requires further investigation. 
WSRC-TR-2005-00182, rev. 0

Page 24 of 37

Figure 7. Mass Concentration of Modifier versus Isopar ${ }^{\circledR} \mathbf{L}$

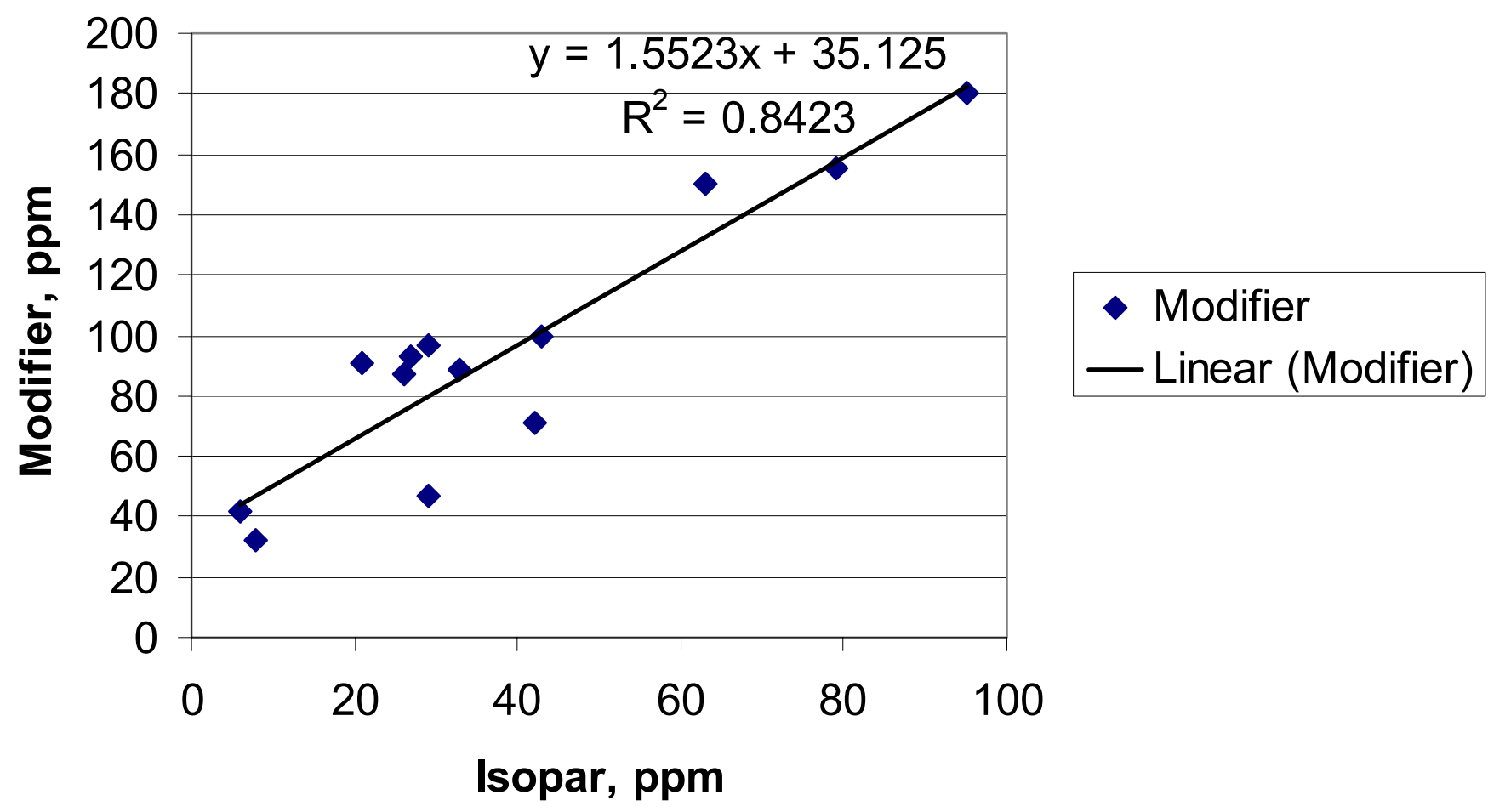

\section{SUMMARY OF RESULTS}

Scoping work performed on an accelerated basis provided organic carryover data from a $2-\mathrm{cm}$ centrifugal contactor bank. The following observations are noted.

- Organic carryover values were within the ranges of those found in prior work. The experiment found that organic carryover after decanting was bounded by $417 \mathrm{ppm}$ of Isopar ${ }^{\circledR} \mathrm{L}$ for the many strip/organic runs that were completed. Carryover did not exceed 88 ppm of Isopar ${ }^{\circledR}$ L for solvent contacted with DSS simulant.

- No organic droplets greater than 18 micron were detected in any of the work. Strip output contained droplets down to 0.5 micron in diameter. Droplets of archive solvent in DSS were almost monodisperse by comparison, having a size range $4.7+/-1.6$ micron in one experiment and 5.2 +/- 0.8 micron in the second sample. This work never found the 100-200 micron size particles reported in ANL work.

- Optical microscopy was successful in obtaining photographs of dispersed organic droplets, confirming Microtrac ${ }^{\circledR}$ S3000 results in a qualitative way. 
- A 0.7 micron fiberglass filter provided significant removal of dispersed organic phase from strip solution. A small stack of coalescer elements did not produce significant organic removal from DSS, however, the material may need several feet of thickness for effective application.

- The Parsons-SRS batch of solvent exhibited no excessive tendency to form an emulsion in the 2-cm centrifugal contactor bank. Performance of this solvent was stable and did not raise questions about its quality. 
WSRC-TR-2005-00182, rev. 0

Page 26 of 37

\section{Appendix A}

\section{Test Plan for 4-Contactor Bank Operation in Support Of MCU Carryover Work Revision 0, 3/14/2005}

Objectives: Primary objectives are to obtain the minimum organic droplet size, the droplet size distribution, and the total organic content from the aqueous strip and salt waste streams produced by a bank of four 2 -cm contactors. The data are expected to represent the difficultto-decant portion of organic in the streams. Secondary objectives are to measure turbidity versus time to compare relative ease of coalescence between strip samples adjusted to different $\mathrm{pH}$ 's, and use of a porous element (initial evaluation of remediation methods).

\section{All conditions:}

- Use the typical Organic/Aqueous ratio specific to strip and DSS solutions (no variation of ratio within type of aqueous). Values are given below.

- Make sure the decanters are not agitated by liquid dropping into them. This shall be done by providing means to wick the input liquid to the side of the decanter to promote slow steady film flow.

- Maintain temperature - do not vary from nominal within the rig. Values are given below.

- Rig is to commence operation with empty decanters so that steady operation is reached more quickly. More than 3 decanter volumes are to be passed through before we look for steady operation. Steady operation will be determined by measurement of turbidity of the aqueous output of the contactor (not decanter). All detailed measurements after steady state is reached will be made on decanter output so that the effect of in-vial decantation of sample is minimized.

Once steady state is reached an aqueous output sample from the decanter receiving the aqueous stream is to be analyzed by optical microscopy, Microtrac ${ }^{\circledR}$, GC-MS for total Isopar ${ }^{\circledR}$ L content, and turbidity. $\mathrm{pH}$ effects upon strip raffinate samples will be examined. A filter or coalescing medium will be applied if available.

\section{Sample Handling Protocol and Issues:}

While samples of aqueous liquid may contain little net organic phase they will still decant/coalesce during collection and further handling. In addition collection takes significant time because of the slow flow rate out of the rig. The following steps are planned to address the difficulties:

1. Notify analysts that samples are coming within hours of delivery.

2. Use only glass vials and separatory funnels so that the aqueous sees primarily waterwettable surfaces. Since vials are to be capped with (oleophilic) Teflon ${ }^{\circledR}$ liners every effort must be made to keep sample liquids from touching the cap (keep vial upright; never tip or shake). 
3. Collect a single composite sample in a way that allows distribution of the same sample to several different vials for analysis, while excluding any organic layer that forms in the funnel. "Time zero" is noted when filling of the separatory funnel commences. Total estimated volume of single sample: $50 \mathrm{~mL}$.

4. In the cases where $\mathrm{pH}$ effects on decantation/coalescence is studied, the $\mathrm{pH}$ adjusting agent is placed into the separatory funnel immediately after the funnel collects sufficient sample for the analyses. Gentle swirling is used to effect mixing without dispersing any bulk organic phase that exists in the funnel. Never upend the funnel.

5. The composite sample is to be aged in the separatory funnel and swirled very gently just before individual samples are dispensed. Homogeneity of the individual samples is essential.

6. Individual samples are dispensed to vials. Note estimated volumes:

a. Microscopy Sample: 3-5 mL

b. Microtrac $\AA$ Sample: $5-10 \mathrm{~mL}$

c. GC-MS Sample: 10-14 mL

d. Turbidity Sample: $20 \mathrm{~mL}$

7. Consistent analysis will probably require mixing of vial contents, except where GC-MS consumes the whole sample. This would be done by gentle swirling of the sample or slow mixing of it using a preferably glass eyedropper.

\section{Plans for Strip Solution:}

Fill the strip and organic reservoirs, follow startup practice, and obtain steady operation with contactor block temperatures Once turbidity, temperature, and any other indications show steady operation and an additional hour passes for steady decanter operation, use a small separator funnel to collect aqueous flow out of the respective decanter.

- Test pH 3 (0.001 M nitric) aqueous at low, nominal, and high flow rates at the specific O/A ratio. Note that changing flow rate changes residence time in the decanters. Nominal flow rates are given in the table above. A high flow rate of double the nominal flow rates is still within the approximately $60 \mathrm{~mL} / \mathrm{min}$ total capacity of these contactors. A low flow rate of half nominal is targeted but may be cancelled if found to be impractical.

- Test pH 3 aqueous at nominal flow, allowing decanter output to flow through a filter or other porous element that is available, with output going into the separatory funnel.

- Test pH 1 aqueous at nominal flow rate to examine effect on drop size. $1 \mathrm{~mL}$ of $5 \mathrm{M}$ nitric acid would be added to the separatory funnel immediately after collection is completed. Mix by gentle swirling or slow stirring with a glass rod. Final $\mathrm{pH}$ verified to be less than 2 by $\mathrm{pH}$ paper.

- Test pH 11 aqueous at nominal flow rate to examine effect on drop size. $1 \mathrm{~mL}$ of $0.1 \mathrm{M}$ $\mathrm{NaOH}$ would be added to the separatory funnel immediately after collection is completed. Mix by gentle swirling or slow stirring with a glass rod. Final $\mathrm{pH}$ checked to be between 10 and 12 by $\mathrm{pH}$ paper. 


\section{Plans for DSS (Salt) Solution, 5.6 M Na+}

Test salt aqueous at nominal and half nominal flow rates at the specific $\mathrm{O} / \mathrm{A}$ ratio - see Table 7. Half nominal is thus $20 \mathrm{~mL} / \mathrm{min}$ salt solution, $7 \mathrm{~mL} / \mathrm{min}$ solvent. Timing of sampling is per Table 8.

Dilution of salt feed with $0.05 \mathrm{M}$ scrub acid was not considered to be enough of a change to pursue right now.

Table 7. Nominal Conditions for Salt Solution and Strip Solution Operations

\begin{tabular}{|l|l|l|l|c|}
\hline Stream & $\begin{array}{l}\text { Flow Rate } \\
+/-\mathbf{2 0} \%\end{array}$ & $\begin{array}{l}\text { Decanter } \\
\text { Volume }\end{array}$ & $\begin{array}{l}\text { Residence } \\
\text { Time }\end{array}$ & $\begin{array}{c}\text { Contactor } \\
\text { Temperature* }\end{array}$ \\
\hline Salt raffinate & $\begin{array}{l}40 \mathrm{~mL} / \mathrm{min} \\
\text { (aqueous) }\end{array}$ & $\begin{array}{l}111 \mathrm{~mL} \\
\text { (aqueous) }\end{array}$ & $2.8 \mathrm{~min}$ & $24+/-3^{\circ} \mathrm{C}$ \\
\hline Solvent & $\begin{array}{l}12.5 \\
\mathrm{~mL} / \mathrm{min} \\
\text { (organic) }\end{array}$ & $\begin{array}{l}65 \mathrm{~mL} \\
\text { (organic) }\end{array}$ & $5.0 \mathrm{~min}$ & \\
\hline $\begin{array}{l}\text { Strip effluent } \\
\text { (SE) }\end{array}$ & $\begin{array}{l}2.5 \mathrm{~mL} / \mathrm{min} \\
\text { (aqueous) }\end{array}$ & $\begin{array}{l}37 \mathrm{~mL} \\
\text { (aqueous) }\end{array}$ & $15.0 \mathrm{~min}$ & $33+/-3^{\circ} \mathrm{C}$ \\
\hline
\end{tabular}

* The rig will have means of influencing temperature of the metal walls of the contactors, and outside surface temperature of the contactors will be kept within the ranges given. No solution preheating is expected because (1) the salt solution reservoir is at room temperature, and (2) the strip solution flow is very slow, probably not enough to influence contactor temperature.

Table 8. Sample Timing

\begin{tabular}{|l|l|c|c|}
\hline Stream & $\begin{array}{l}\text { Flow Rate } \\
+/-\mathbf{2 0} \%\end{array}$ & $\begin{array}{c}\text { Target time between } \\
\text { "time zero" and analyses* }\end{array}$ & $\begin{array}{c}\text { Nominal Sampling } \\
\text { Time }\end{array}$ \\
\hline Salt raffinate & $\begin{array}{l}40 \mathrm{~mL} / \mathrm{min} \\
\text { (aqueous) }\end{array}$ & 60 minutes & $1.3 \mathrm{~min}$ \\
\hline Strip raffinate & $\begin{array}{l}2.5 \mathrm{~mL} / \mathrm{min} \\
\text { (aqueous) }\end{array}$ & 120 minutes & $20.0 \mathrm{~min}$ \\
\hline
\end{tabular}

* Attempt to control this as a constant despite changes in nominal sampling time with flow rate and other factors beyond our control. GC-MS is exempt from this requirement because it is not a measurement of physical state and it consumes the whole sample, including cleanout of the vial. 
WSRC-TR-2005-00182, rev. 0

Page 29 of 37

\section{Modifications:}

Subsequent to the issuance of this summary workscope modifications below were made with reasons given:

1. Strip/organic runs never exceeded the $12.5 / 2.5 \mathrm{~mL} / \mathrm{min}$ rates above because stable operation was not found for higher flow rates. Strip/organic runs were therefore at nominal, half nominal, and three-quarters nominal.

2. Rig stability dictated half-nominal flow rates of DSS and solvent. Operation was considered stable when no aqueous phase was seen to deposit into the organic decanter.

3. A second batch of solvent was brought into this workscope because the Parsons-SRS solvent exhibited an emulsification problem in the V-5 contactor. The 2-cm contactor rig was thus cleaned and operated with Parsons-SRS solvent along with fresh prefiltered aqueous strip solution to see if problems with emulsions would appear.

4. An extra experiment on 3/31/05 used archive solvent and DSS simulant so that solvent dispersed in aqueous could be produced for the sake of coalescer testing.

5. Use of turbidity to determine steady state of the rig focused on aqueous decanter output rather than input because input liquid turbidity decreased rapidly with time. 
WSRC-TR-2005-00182, rev. 0

Page 30 of 37

\section{Appendix B}

\section{Organic Droplet Size Data Expressed as Volume Fractions}

\begin{tabular}{|c|c|c|c|c|c|c|c|c|}
\hline \multirow[t]{2}{*}{$\begin{array}{l}\text { Sample } \\
\text { Number }\end{array}$} & \multirow{2}{*}{$\begin{array}{c}\text { Aqu- } \\
\text { eous } \\
\text { Phase } \\
\end{array}$} & \multirow[t]{2}{*}{$\begin{array}{l}\text { Organic } \\
\text { Solvent }\end{array}$} & \multicolumn{6}{|c|}{$\begin{array}{l}\text { Fraction of droplets less than indicated diameter in microns } \\
\text { (values are additive) }\end{array}$} \\
\hline & & & $1.0 \mu$ & $5.5 \mu$ & $7.8 \mu$ & 11. $\mu$ & $13.1 \mu$ & $18.5 \mu$ \\
\hline 1 & Strip & archive & No data & & & & & \\
\hline 2 & Strip & archive & 0.124 & 0.367 & 0.570 & 0.763 & 0.914 & 0.998 \\
\hline 3 & Strip & archive & No data & & & & & \\
\hline 4 & Strip & archive & 0.0034 & 0.469 & 0.646 & 0.933 & 0.983 & 1.000 \\
\hline 5 & Strip & archive & 0.0024 & 0.454 & 0.608 & 0.877 & 0.951 & 0.999 \\
\hline 6 & Strip & archive & No data & & & & & \\
\hline 7 & Strip & archive & 0.042 & 0.952 & 0.999 & 1.000 & 1.000 & 1.000 \\
\hline 8 & Strip & archive & 0.0349 & 0.402 & 0.508 & 0.840 & 0.947 & 1.000 \\
\hline 9 & Strip & archive & 0.000 & 0.630 & 0.919 & 1.000 & 1.000 & 1.000 \\
\hline 10 & Strip & archive & 0.211 & 0.881 & 1.000 & 1.000 & 1.000 & 1.000 \\
\hline 11 & Strip & archive & 0.000 & 0.194 & 0.437 & 0.620 & 0.936 & 1.000 \\
\hline 12 & Strip & archive & 0.251 & 0.616 & 0.753 & 0.883 & 0.953 & 0.988 \\
\hline 13 & Strip & archive & 0.000 & 0.520 & 0.684 & 0.919 & 0.973 & 1.000 \\
\hline 14 & Strip & archive & No data & & & & & \\
\hline 15 & DSS & archive & 0.000 & 0.843 & 1.000 & 1.000 & 1.000 & 1.000 \\
\hline 16 & DSS & archive & 0.000 & 0.807 & 1.000 & 1.000 & 1.000 & 1.000 \\
\hline 17 & Strip & Parsons & 0.000 & 0.887 & 0.997 & 1.000 & 1.000 & 1.000 \\
\hline 18 & Strip & Parsons & 0.000 & 0.944 & 1.000 & 1.000 & 1.000 & 1.000 \\
\hline 19 & DSS & archive & $0.000 *$ & 0.828 & 1.000 & 1.000 & 1.000 & 1.000 \\
\hline 20 & DSS & archive & $0.000^{*}$ & 0.586 & 1.000 & 1.000 & 1.000 & 1.000 \\
\hline
\end{tabular}

"Parsons" organic solvent refers to recovered Parsons-SRS solvent loaned to SRNL.

"No Data" for Microtrac ${ }^{\circledR}$ droplet size indicates that the sample had too few droplets to report any PSD, or that a Microtrac ${ }^{\circledR}$ measurement of a duplicated sample was not made. Only one Microtrac $^{\circledR}$ measurement was made (Samples 2 and 5) while Samples 3 and 6 were duplicates of 2 and 5 submitted for second SVOA measurements.

* Microtrac ${ }^{\circledR}$ signal strength for data in indicated rows is borderline low, but a droplet size distribution was acquired and its product with Isopar ${ }^{\circledR} \mathrm{L}$ level is reported here. 


\author{
Appendix C \\ Optical Micrographs of Samples
}

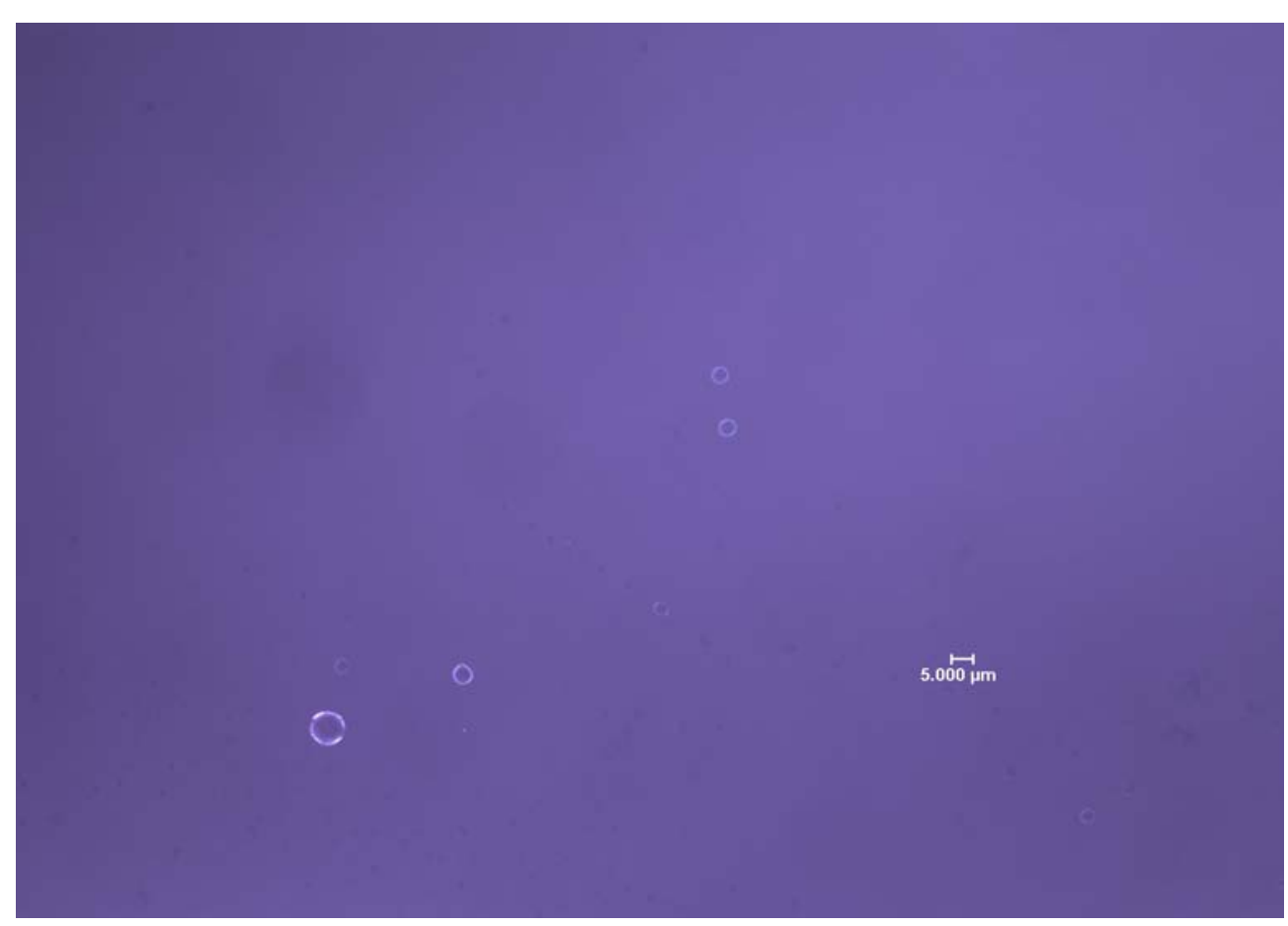

Figure 8. Optical Micrograph of Sample 4, 500X 


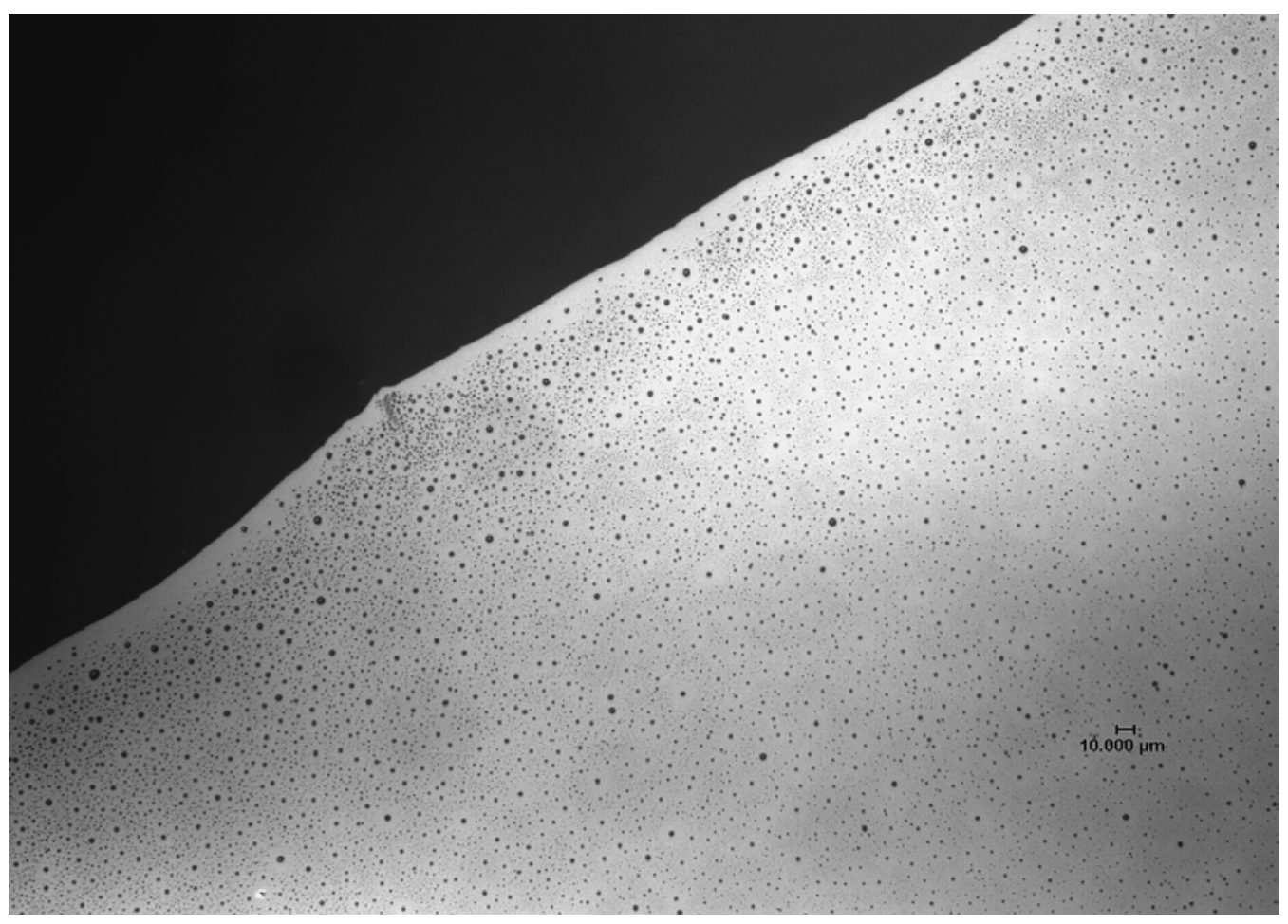

Figure 10. Optical Micrograph of Sample 6, 500X

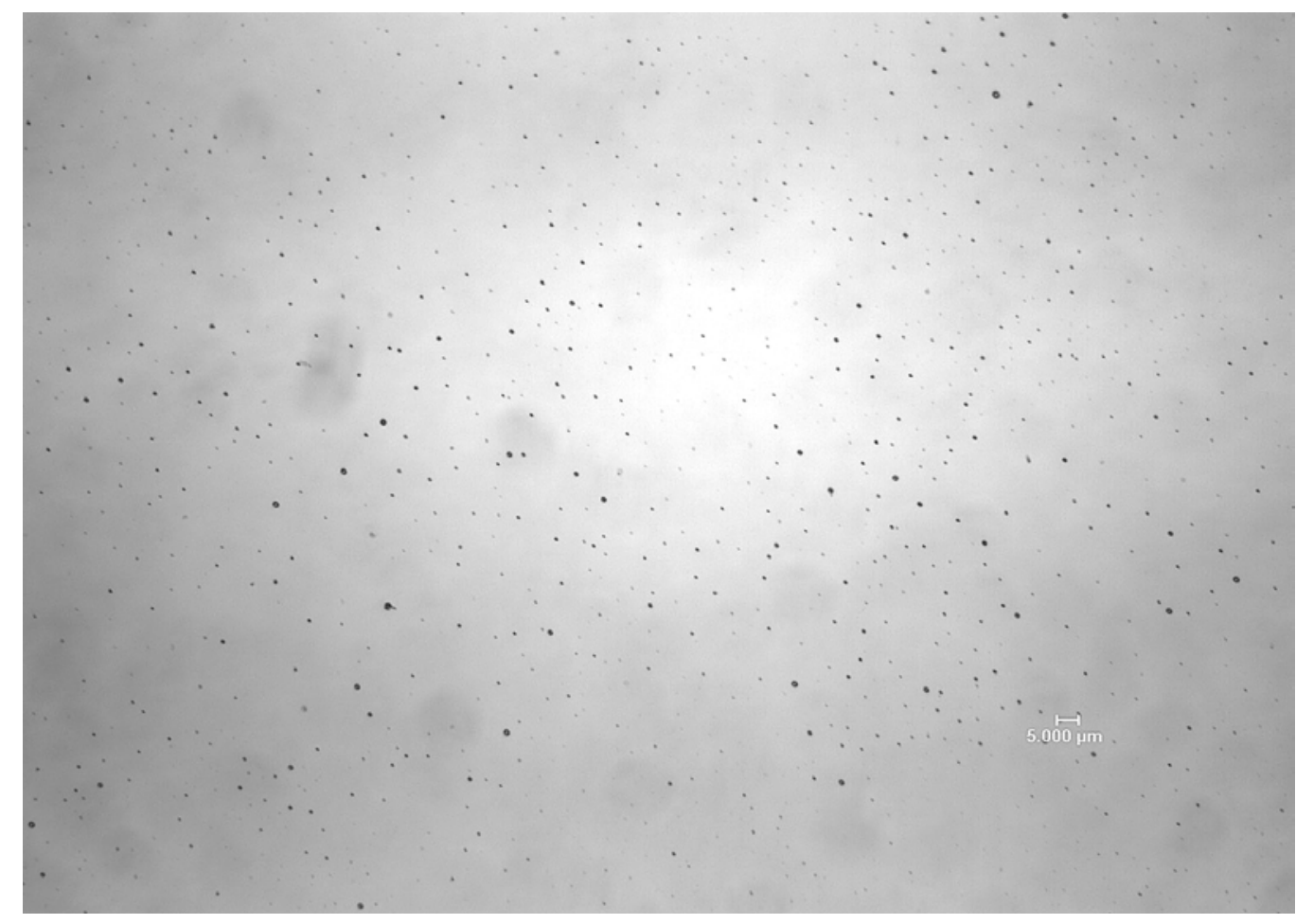

Figure 11. Optical Micrograph of Sample 7, 500X 


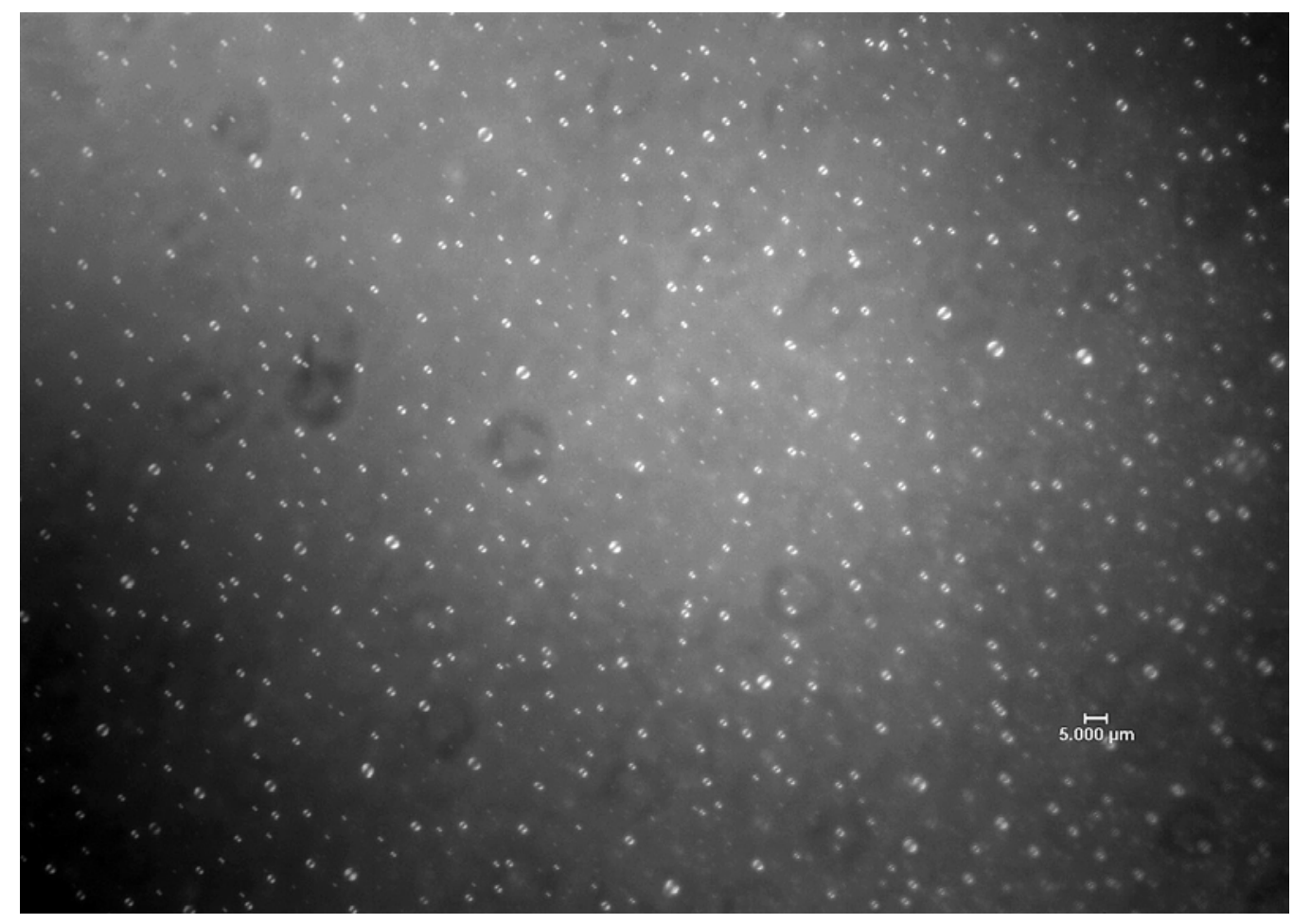

Figure 12. Optical Micrograph of Sample 8, 500X

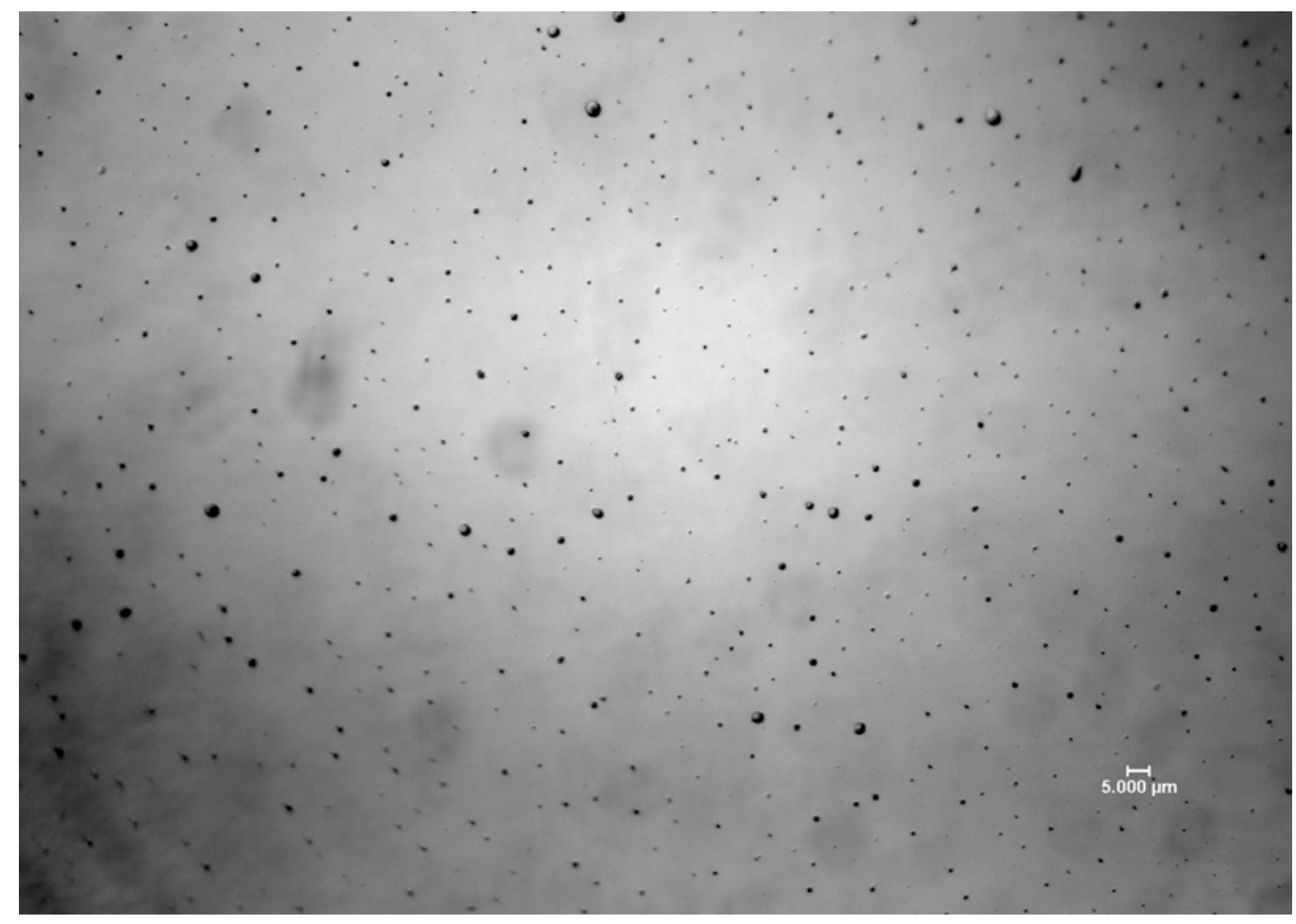

Figure 13. Optical Micrograph of Sample 11, 500X 


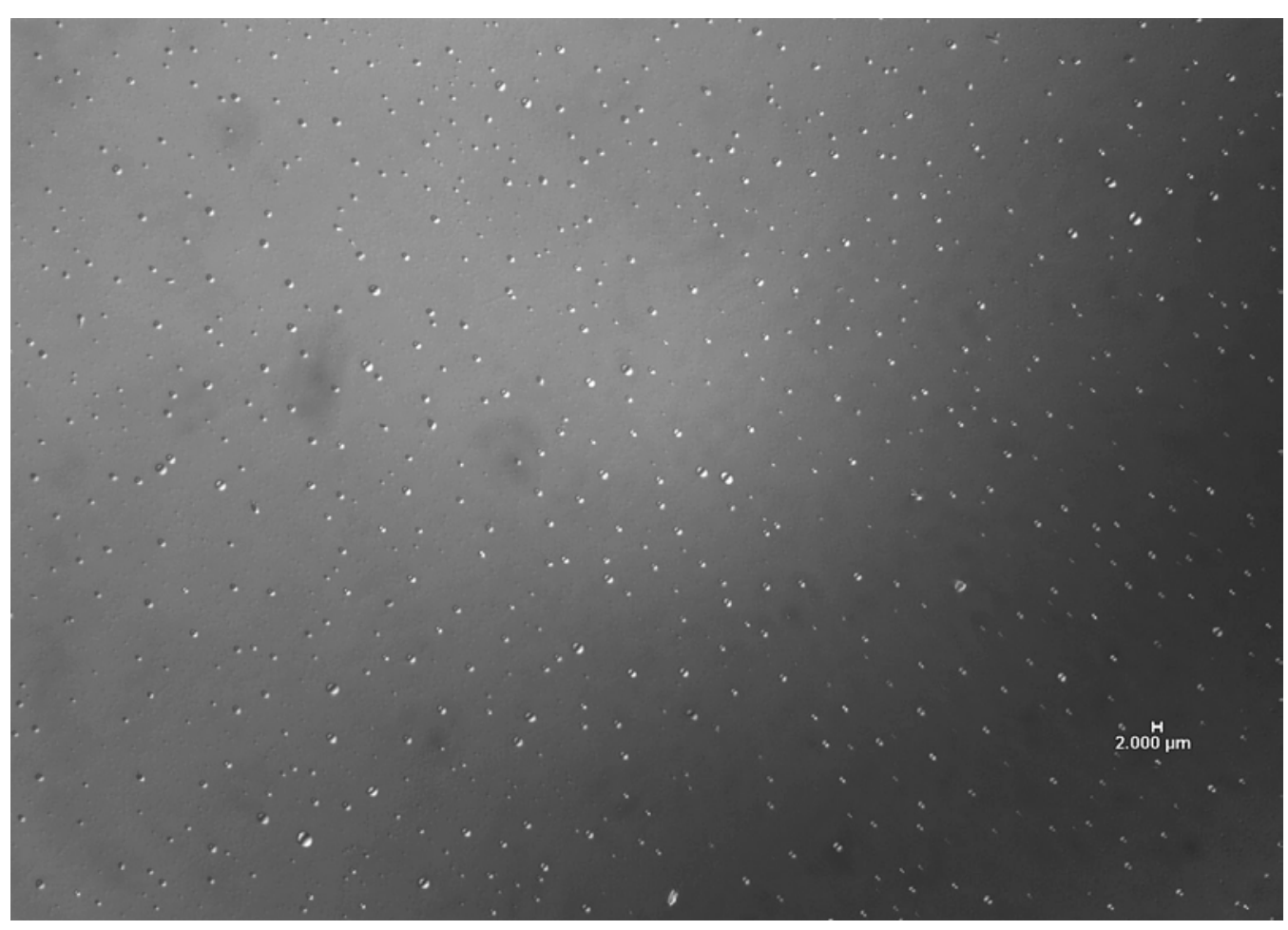

Figure 14. Optical Micrograph of Sample 12 at 500X

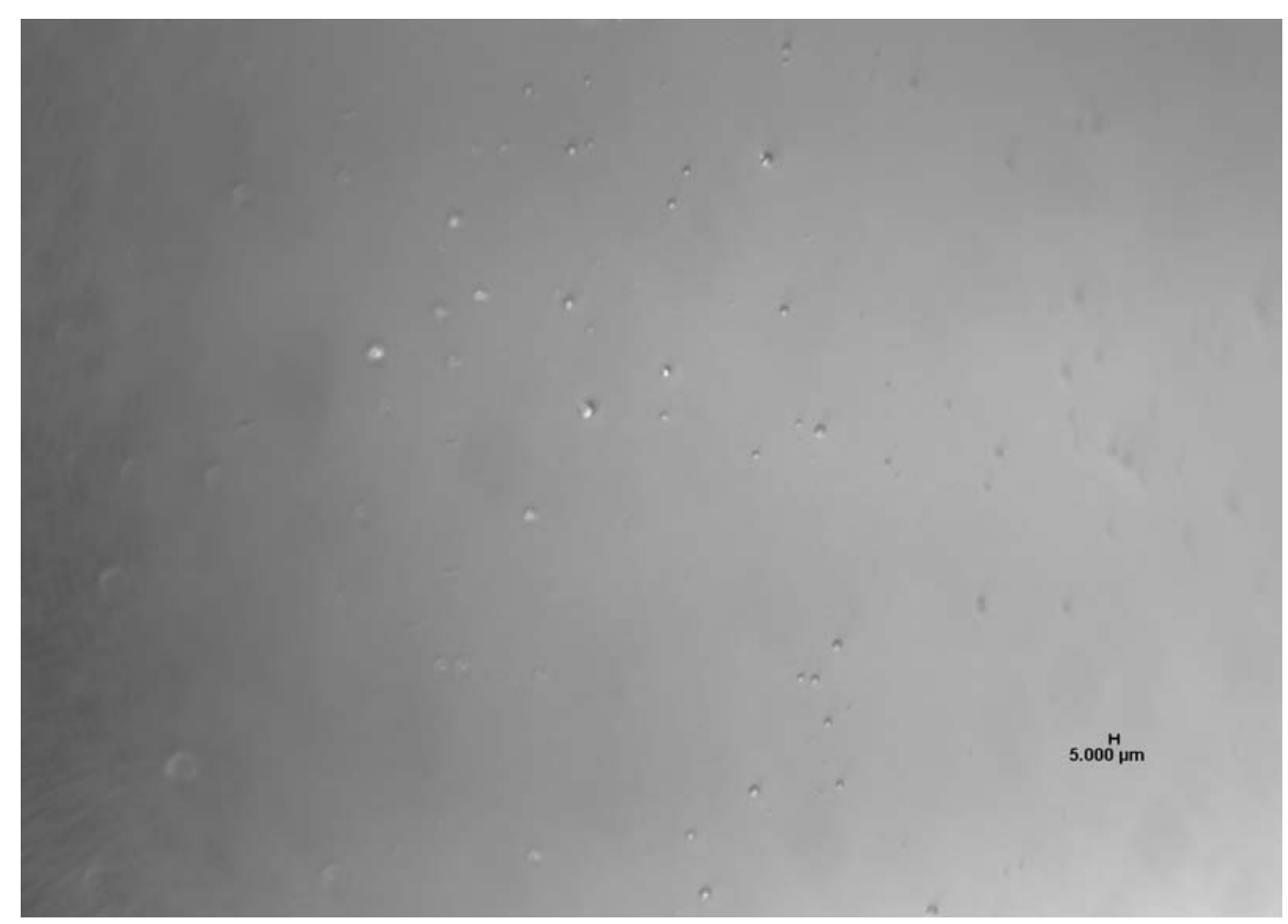

Figure 15. Optical Micrograph of Sample 15 at 500X 
WSRC-TR-2005-00182, rev. 0

Page 35 of 37

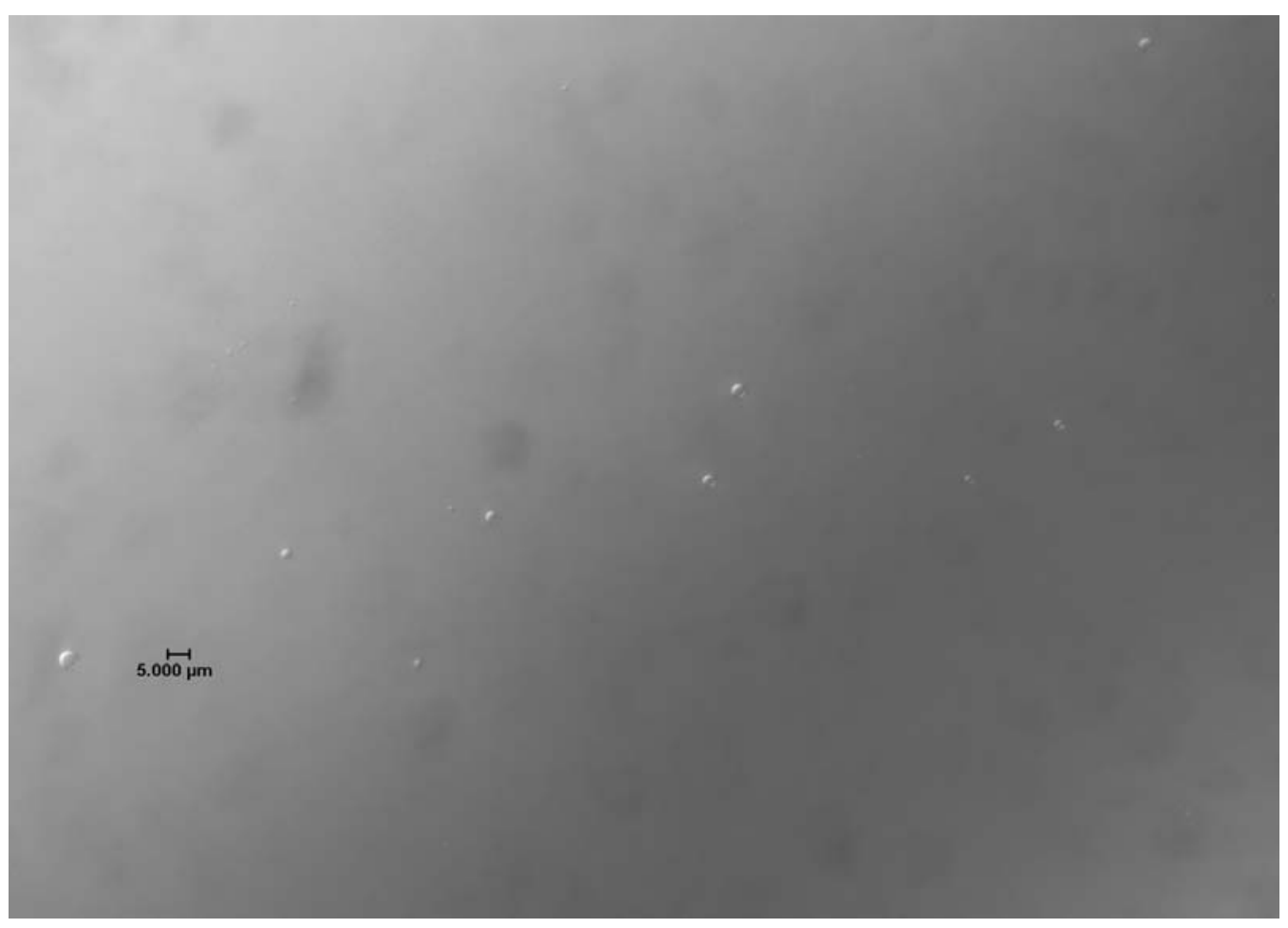

Figure 16. Optical Micrograph of Sample 16 at 500X 
WSRC-TR-2005-00182, rev. 0

Page 36 of 37

\section{REFERENCES}

${ }^{1}$ A. Giordano, Project Early Warning, February 14, 2005.

2 S. J. Robertson and B. A. Gifford, "Charter for the CSSX Solvent Integration Team", CBUPIT-2005-00035, Rev. 0, February 15, 2005.

${ }^{3}$ S. D. Fink, M. L. Restivo, M. D. Fowley, D. B. Burns, S. L. Crump, W. M. Smith, Jr., T. B. Peters, F. F. Fondeur, D. T. Herman, M. A. Norato, and C. A. Nash, "Entrainment of Solvent in Aqueous Stream from CINC V-5 Contactor," WSRC-TR-2005-00187, April 29, 2005.

${ }^{4}$ D. D. Walker, S. G. Campbell, C. W. Kennell, R. A. Leonard, M. W. Geeting, W. R. Wilmarth, M. A. Norato, R. A. Pierce, J. D. Law, T. A. Todd, "Demonstration of Caustic Side Solvent Extraction with Savannah River Site High Level Waste", WSRC-TR-2001-00223, April 19, 2001.

5 D. D. Walker, S. L. Crump, M. A. Norato, R. A. Pierce, R. J. Ray, T. L. White, "Demonstration of Caustic Side Solvent Extraction with Savannah River Site High Level Waste: Results of Organic and Trace Component Analysis", WSRC-TR-2001-00372, December 1, 2001.

${ }^{6}$ M. A. Norato, D. D. Walker, S. G. Campbell, M. L. Crowder, M. W. Geeting, G. F. Kessinger, R. A. Pierce, "High Level Waste Demonstration of the Caustic-Side Solvent Extraction with Optimized Solvent in the 2-CM Centrifugal Contactor Apparatus using Tank 37H/44F Supernate", WSRC-TR-2002-00243, November 1, 2002.

${ }^{7}$ M. A. Norato, S. D. Fink, F. F. Fondeur, G. F. Kessinger, R. A. Pierce, D. D. Walker, "Demonstration of Caustic-Side Solvent Extraction with Optimized Solvent in the 2-cm Centrifugal Contactor Apparatus Using Dissolved Saltcake from Tank 37H”, WSRC-TR2002-00307, rev. 1, September 3, 2002.

${ }^{8}$ H. A. Arafat, M. C. Hash, A. S. Hebden, and R. A. Leonard, "Characterization and Recovery of Solvent Entrained during Use of Centrifugal Contactors", ANL-02/08, October 2001.

9 C. Pereira, H. A. Arafat, J. R. Falkenburg, M. C. Regalbuto, and G. F. Vandegrift, "Recovery of Entrained CSSX Solvent from Caustic Aqueous Raffinate using Coalescers", ANL-02/34, November 2002.

${ }^{10}$ Manual L1, “Control of Technical Work”, Procedure 7.10, revision 4, section 5.9.1, procedure effective June 17, 2002.

${ }^{11}$ H. H. Saito, "Salt Alternatives Program: Filtration Studies", Laboratory notebook WSRCNB-99-00205, opened August 18, 1999.

12 "Savannah River National Laboratory Conduct of Research and Development", WSRCIM-97-00024, revision 3.0, June 2004.

13 J. H. Gillam, "Notice of NEPA Approval (NONA)", SRNL-ESD-2005-00043, March 7, 2005.

${ }^{14}$ C. A. Nash and W. D. King, "Preliminary Investigation of CSSX Organic Solvent Drop Size”, SRNL-LWP-2005-00006, January 19, 2005.

15 Manual L16.1 Procedure \# ADS-1119, "Procedure for Operating the Microtrac S3000 Particle Size Analyzer (U)", Rev. 0, Effective Date: July 15, 2003.

16 Waste Processing Technology Manual L12.1, "Calibration of Orbeco-Hellige Turbidity Meters", IWT-OP-138. 
17 D. D. Walker, S. G. Campbell, C. W. Kennell, R. A. Leonard, M. W. Geeting, W. R. Wilmarth, M. A. Norato, R. A. Pierce, J. D. Law, T. A. Todd, "Demonstration of Caustic Side Solvent Extraction with Savannah River Site High Level Waste", WSRC-TR-2001-00223, April 19, 2001.

${ }^{18}$ R. A. Leonard, "Proof-of-Concept Tests for Caustic-Side Solvent Extraction of Cesium from Tank Waste", ANL-00/30, November, 2000.

${ }^{19}$ D. D. Walker, S. G. Campbell, C. W. Kennell, R. A. Leonard, M. W. Geeting, W. R.

Wilmarth, M. A. Norato, R. A. Pierce, J. D. Law, T. A. Todd, "Demonstration of Caustic Side Solvent Extraction with Savannah River Site High Level Waste”, WSRC-TR-2001-00223, April 19, 2001.

${ }^{20}$ M. R. Poirier, D. T. Herman, P. R. Burket, T. B. Peters, S. M. Serkiz, and S. D. Fink, "Testing of the In Situ, Mixed Iron Oxide (IS-MIO) Alpha Removal Process", WSRC-TR2004-00283, June 29, 2004.

${ }^{21}$ D. T. Hobbs, M. S. Blume, and H. L. Thacker, "Phase V Simulant Testing of Monosodium Titanate Adsorption Kinetics," WSRC-TR-2000-00142, May 24, 2000.

22 B. A. Moyer, S. D. Alexandratos, P. V. Bonnesen, G. M. Brown, J. E. Caton Jr., L. H. Delmau, C. R. Duchemin, T. J. Haverlock, T. G. Levitskaia, M. P. Maskarinec, F. V. Sloop Jr., and C. L. Stine, "Caustic-Side Solvent Extraction Chemical and Physical Properties Progress in FY2000 and FY2001”, ORNL/TM-2001/285, February 2002. 
WSRC-TR-2005-00182, Rev. 0

Distribution

\begin{tabular}{|c|c|c|c|c|c|c|c|}
\hline R. A. & Adams & 241-162H, Rm. 4 & (E) & D. B. & Little & 703-H, Rm. 3 & (E) \\
\hline J. W. & Barber & 704-2H, Rm. 197 & (E) & S. R. & Loflin & 773-41A, Rm. 223 & (E) \\
\hline J. L. & Barnes & 704-S, Rm. 19 & (E) & N. P. & Malik & 704-26F, Rm. 11 & (E) \\
\hline M. J. & Barnes & 773-A, Rm. B-132 & (E) & J. C. & Marra & 773-42A, Rm. 173 & (E) \\
\hline W. M. & Barnes & 704-56H, Rm. 164 & (E) & J. E. & Marra & 773-A, Rm. A-263 & (P) \\
\hline S. M. & Blanco & 766-H. Rm. 2434 & (E) & D. J. & Martin & 703-H, Rm. 84 & (E) \\
\hline L. R. & Bragg & 766-H, Rm. 2434 & (E) & K. B. & Martin & 773-42A, Rm. 14 & (E) \\
\hline T. E. & Britt & 742-4G, Rm. 3 & (E) & C. J. & Martino & 735-11A, Rm. 121 & (E) \\
\hline H. L. & Bui & 742-4G, Rm. 3 & (E) & G. A. & Mathis & 724-9E, Rm. 1 & (E) \\
\hline S. G. & Campbell & 703-H, Rm. 107 & (E) & G. J. & Matis & 766-H, Rm. 1066F & (E) \\
\hline L. & Carey & 766-H, Rm. 2005A & (E) & D. & Maxwell & 766-H, Rm. 2231 & (E) \\
\hline J. T. & Carter & 703-H, Rm 122 & (E) & D. J. & McCabe & 773-42-A, Rm. 153 & (E) \\
\hline W. D. & Clark & 766-H, Rm. 2412 & (E) & J. W. & McCullough & 766-H, Rm. 2411 & (E) \\
\hline S. L. & Clifford & 766-H, Rm. 2443 & (E) & L. T. & McGuire & 766-H, Rm. 2441 & (E) \\
\hline J. J. & Connelly & 773-41A, Rm. 231 & (E) & M. S. & Miller & 772-7B, Rm. 6 & (E) \\
\hline D. T. & Conrad & 766-H, Rm. 2007 & (E) & R. M. & Mobley & 703-H, Rm. 16 & (E) \\
\hline D. R. & Cox & 730-2B, Rm. 118 & (E) & C. A. & Nash & 773-42A, Rm. 182 & (E) \\
\hline A. D. & Cozzi & 773-43A, Rm. 218 & (E) & L. M. & Nelson & 773-43A, Rm. 222 & (E) \\
\hline C. L. & Crawford & 773-41A, Rm. 180 & (E) & M. A. & Norato & 704-27S, Rm. 6 & (E) \\
\hline D. A. & Crowley & 773-A, Rm. A-262 & (E) & M. R. & Norton & 766-H, Rm. 2002 & (E) \\
\hline N. R. & Davis & 766-H, Rm. 1006 & (E) & J. E. & Occhipinti & 704-S, Rm. 18 & (E) \\
\hline W. B. & Dean & 766-H, Rm. 2243 & (E) & L. D. & Olson & 703-H, Rm. 5 & (E) \\
\hline V. G. & Dickert & 703-H, Rm. 4 & (E) & T. B. & Peters & 773-42A, Rm. 128 & (E) \\
\hline C. L. & Donahue & 241-162H, Rm. 6 & (E) & J. A. & Pike & 703-H, Rm. 99 & (E) \\
\hline M. D. & Drumm & 766-H, Rm. 2050 & (E) & M. R. & Poirier & 773-42A, Rm. 123 & (E) \\
\hline M. C. & Duff & 773-43A, Rm. 217 & (E) & S. H. & Reboul & 703-H, Rm. 84 & (E) \\
\hline C. R. & Dyer & 766-H, Rm. 2426 & (E) & T. R. & Reynolds & 704-S, Rm. 65 & (E) \\
\hline R. E. & Eibling & 999-W, Rm. 335 & (E) & M.A. & Rios-Armstron & 766-H, Rm 2054 & (E) \\
\hline G. N. & Eide & 241-121H, Rm. 6 & (E) & S. J. & Robertson & 766-H, Rm. 2500 & (P) \\
\hline H. H. & Elder & 703-H, Rm. 95 & (E) & B. C. & Rogers & 766-H, Rm. 2008 & (E) \\
\hline S. D. & Fink & 773-A, Rm. B-112 & $(E, P)$ & R. A. & Runnels & 766-H, Rm. 2011 & (E) \\
\hline F. F. & Fondeur & 773-A, Rm. B-124 & (E) & P. J. & Ryan & 704-61S, Rm. 6 & (E) \\
\hline R. C. & Fowler & 703-H, Rm. 98 & (E) & E. & Saldivar & 766-H, Rm. 2004 & (E) \\
\hline L. M. & Fox & 703-H, Rm. 3 & (E) & S. C. & Shah & 766-H, Rm. 2037 & (E) \\
\hline M.W. & Geeting & 766-H, Rm. 2035 & (E) & D. C. & Sherburne & 704-S, Rm. 18 & (E) \\
\hline B. A. & Gifford & 766-H, Rm. 1066D & (E) & T. J. & Spears & 766-H, Rm. 2015 & (E) \\
\hline A. P. & Giordano & 703-H, Rm 79 & (E) & R. H. & Spires & 766-H, Rm. 2003 & (E) \\
\hline J. C. & Griffin & 773-A, rm. A-231 & (E) & M. E. & Stallings & 773-A, Rm. B-117 & (E) \\
\hline H. D. & Harmon & 766-H, Rm. 2014 & (P) & W. E. & Stevens & 773-A, Rm. A-261 & (E) \\
\hline K. D. & Harp & 755-H, Rm. 1066B & (E) & S. J. & Strohmeier & 766-H, Rm. 2022 & (E) \\
\hline E. W. & Harrison & 766-H, Rm. 2034 & (E) & S. G. & Subosits & 766-H, Rm. 2052 & (E) \\
\hline K. A. & Hauer & 703-H, Rm. 11 & (E) & P. C. & Suggs & 766-H, Rm. 2436 & (E) \\
\hline D. T. & Herman & 735-11A, Rm. 104 & (E) & G. A. & Taylor & 703-H, Rm. 96 & (E) \\
\hline R. N. & Hinds & 766-H, Rm. 2430 & (E) & S. A. & Thomas & 766-H, Rm. 2016 & (E) \\
\hline D. T. & Hobbs & 773-A, Rm. B-117 & (E) & P. J. & Valenti & 730-4B, Rm. 2062 & (E) \\
\hline E. W. & Holtzscheiter & 773-A, Rm. A-230 & (E) & W. B. & Van-Pelt & 704-S, Rm. 16 & (E) \\
\hline C. M. & Jantzen & 773-A, Rm. B-104 & (E) & D. D. & Walker & 773-A, Rm. B-124 & (E) \\
\hline R. T. & Jones & 766-H, Rm. 2463 & (E) & A. $\mathrm{O}$. & Waring & 766-H, Rm. 2423 & (E) \\
\hline W. D. & Kerley & 766-H, Rm. 2010 & (E) & F. A. & Washburn & 766-H, Rm. 2054 & (E) \\
\hline
\end{tabular}


WSRC-TR-2005-00182, Rev. 0

\begin{tabular}{|c|c|c|c|c|c|c|}
\hline E. T. & Ketusky & 703-H, Rm. 83 & $(\mathrm{E})$ & V. B. Wheeler & 766-H, Rm. 2438 & (E) \\
\hline D. P. & Lambert & 773-A, Rm. B-132 & (E) & G. G. Wicks & 773-A, Rm. B-129 & (E) \\
\hline C. A. & Lanigan & 766-H, Rm. 2440B & (E) & W. R. Wilmarth & 773-42A, Rm. 171 & (E) \\
\hline C. A. & Langton & 773-43A, Rm. 219 & (E) & G. C. Winship & 766-H, Rm. 2024 & (E) \\
\hline T. T. & Le & 766-H, Rm. 2237 & (E) & LWP File & $773-42 \mathrm{~A}$ & $(E, P)$ \\
\hline R. K. & Leugemors & 766-H, Rm. 2013 & (E) & STI & $703-43 A$ & (E) \\
\hline P. D. & d'Entremont & 766-H, Rm. 2208 & (E) & & & \\
\hline W. G. & Dyer & 766-H, Rm. 2246 & (E) & & & \\
\hline R. A. & Eubanks & 707-7F, Rm. 116 & (E) & & & \\
\hline N. & Shanmuganath: & : 245-9F, Rm. 8 & (E) & & & \\
\hline W. B. & Brasel & PARSONS & (E) & & & \\
\hline W. M. & Howell & 766-H, Rm. 2023 & (E) & & & \\
\hline E. A. & Brass & 730-1B, Rm. 2084 & (E) & & & \\
\hline M. R. & Gober & 730-1B, Rm. 216 & (E) & & & \\
\hline D. K. & Noller & 740-11A, Rm. 5 & (E) & & & \\
\hline S. J. & Brown & 730-1B, Rm. 2071 & (E) & & & \\
\hline P. S. & Mukherjee & 245-9F, Rm. 10 & (E) & & & \\
\hline V.P. & LeDonne & 730-1B, Rm. 2075 & (E) & & & \\
\hline J. K. & Jeffrey & 703-H, Rm. 98 & (E) & & & \\
\hline M. J. & Barnes & 773-A, Rm. C-152 & (E) & & & \\
\hline
\end{tabular}

*Our standard distribution format is electronic unless otherwise requested

(E) Electronic

(P) Paper Mail 